\title{
Numerical optimization of a fin-tube gas to liquid heat exchanger
}

\author{
Levent Bilira ${ }^{\mathrm{a}, *}$, Zafer İlken ${ }^{\mathrm{b}}$, Aytunç Erek ${ }^{\mathrm{c}}$ \\ a Department of Industrial Engineering, Anadolu University, İki Eylül Campus, 26555 Eskişehir, Turkey \\ ${ }^{\mathrm{b}}$ Department of Mechanical Engineering, Izmir Institute of Technology, Urla, 35430 Izmir, Turkey \\ ${ }^{\mathrm{c}}$ Department of Mechanical Engineering, Dokuz Eylül University, Bornova, 35100 Izmir, Turkey
}

\section{A R T I C L E I N F O}

\section{Article history:}

Received 23 May 2011

Received in revised form

12 September 2011

Accepted 19 September 2011

Available online 14 October 2011

\section{Keywords:}

Heat transfer enhancement

Heat exchanger

Protrusions

\begin{abstract}
A B S T R A C T
The influence of plate fin, fin tube and protrusion parameters on heat transfer and pressure drop characteristics of a finned tube gas to liquid heat exchanger is examined in this study. The optimization of plate fin, fin tube and protrusion dimensions as well as protrusion locations on plate fin surface is performed numerically using a computational fluid dynamics (CFD) program named "Fluent". The dimensions of the plate fin of a commercially available combi boiler apparatus heat exchanger are taken as basic dimensions. As the first step, the best plate fin and fin tube geometry is determined. Secondly, the best dimensions for three different protrusions (balcony, winglet and imprint) and their most suitable locations on the plate fin surface are found. Finally, the cumulative effects of several combinations of these three protrusions on the plate fin surface are analyzed. The placement combinations of protrusions are decided according to the results obtained for the individual effect of each protrusion. The fin named as I5B2W3 is found to be the most efficient fin among the investigated cases. A comparison with a numerical and computational study is also performed to validate the numerical results of the present study.
\end{abstract}

(c) 2011 Elsevier Masson SAS. All rights reserved.

\section{Introduction}

Heat exchangers, which enable the heat transfer between two flows, have a wide usage area such as power production, waste heat recovery, air conditioning, domestic heating appliances etc. One of the most important types is fin-tube gas to liquid heat exchanger. Generally, a liquid flow inside the tubes is heated or cooled by a gas flow at different temperature, which passes through the fins of the heat exchanger. The fins provide extra heat transfer area for the heat exchange between two flows. However, since the thermal resistance at the gas side is high, the heat exchange is limited. In order to increase the heat transfer performance of fin-tube heat exchangers many researchers examined the effects of geometrical parameters of plate fins and tubes. Rocha et al. [1] made a two dimensional heat transfer investigation about the ellipticity of the tubes of plate fin heat exchangers. They reported that as the tube ellipticity value is increased, the efficiency of the heat exchanger is improved. Kundu and Das [2] gave the dimensions of a plate fin which accomplish the maximum heat transfer for a constant volume in their study. Mendez et al. [3] performed a numerical and experimental investigation about the influence of the fin spacing on

\footnotetext{
* Corresponding author. Tel.: +90 22232135 50/6439; fax: +90 2223239501. E-mail address: lbilir@anadolu.edu.tr (L. Bilir).
}

heat transfer and pressure drop values of a plate fin and circular tube heat exchanger. Saboya and Saboya [4] used naphthalene sublimation technique to calculate the average convective heat transfer coefficient for a plate fin and elliptic tube heat exchanger. They reported that elliptical tubes provide better overall performance than circular ones. Kim and Song [5] made naphthalene sublimation experiments for a plate fin and circular tube heat exchanger. The experiments reveal that when the tube is placed in a downstream position and when the gap between the fins is decreased, better heat transfer is accomplished. Erek et al. [6] performed a numerical study for a plate fin heat exchanger with one row tube configuration and fixed flue gas mass flow rate. They observed heat transfer enhancement when the distance between fins is decreased, when the fin tube is shifted to downstream region, when the fin height is increased, when thin fins are used and when elliptical tubes replace circular ones.

The studies given above investigated only the geometry of plate fin and tube. The fin shape is also an important parameter which can influence the heat transfer and pressure drop values of a heat exchanger. Hence, the fin shape also took the interest of many researchers. Wang et al. [7] examined 18 different fin and tube heat exchangers with wavy fin pattern in a wind tunnel. Abu Madi et al. [8] tested plate and corrugated fins experimentally. They derived correlations for Colburn $\mathrm{j}$ and friction factors including all variables investigated in their study. Yan and Sheen [9] compared plate, wavy 


\begin{tabular}{|c|c|c|c|}
\hline \multicolumn{2}{|c|}{ Nomenclature } & $P$ & perimeter, m \\
\hline$a$ & greater radius of fin tube ellipse, $\mathrm{mm}$ & $r$ & imprint type protrusion radius, $\mathrm{mm}$ \\
\hline$A$ & cross sectional area, $\mathrm{m}^{2}$ & $\operatorname{Re}$ & Reynolds number \\
\hline$b$ & smaller radius of fin tube ellipse, $\mathrm{mm}$ & $t$ & fin tube thickness, $\mathrm{mm}$ \\
\hline$d$ & wave height, mm & $T$ & temperature, $\mathrm{K}$ \\
\hline$D_{\mathrm{h}}$ & hydraulic diameter, mm & $V$ & velocity, m/s \\
\hline$h$ & balcony type protrusion height, $\mathrm{mm}$ & $w$ & winglet type protrusion width, $\mathrm{mm}$ \\
\hline$h$ & convection coefficient, $\mathrm{W} / \mathrm{m}^{2} \mathrm{~K}$ & & \\
\hline$k$ & thermal conductivity, $\mathrm{W} / \mathrm{mK}$ & \multicolumn{2}{|l|}{ Subscripts } \\
\hline$l$ & distance, $\mathrm{m}$ & flue gas & for flue gas \\
\hline$L$ & fin height, mm & water & for water \\
\hline$L_{1}$ & fin tube location on fin, $\mathrm{mm}$ & & \\
\hline$L_{\mathrm{b}}$ & balcony type protrusion length, $\mathrm{mm}$ & Greek & \\
\hline$L_{\mathrm{w}}$ & ringlet type protrusion length, $\mathrm{mm}$ & $\theta$ & winglet angle of attack, ${ }^{\circ}$ \\
\hline$L_{\mathrm{i}}$ & imprint type protrusion length, $\mathrm{mm}$ & $\mu$ & dynamic viscosity, $\mathrm{kg} / \mathrm{ms}$ \\
\hline$\dot{m}$ & mass flow rate, $\mathrm{kg} / \mathrm{s}$ & $\rho$ & density, $\mathrm{kg} / \mathrm{m}^{3}$ \\
\hline $\mathrm{Nu}$ & Nusselt number & & \\
\hline
\end{tabular}

and louvered fin performances by using area goodness factor and volume goodness factor in their experimental study. Lozza and Merlo [10] carried out an experimental study on the heat transfer and pressure drop performances of 15 different heat exchangers with diverse fin types. They reported that louvered fin is the best, wavy fin is the second and corrugated fin is the worst in terms of heat transfer performance. Pirompugd et al. [11] performed the tests of 18 wavy fin and tube heat exchangers in a wind tunnel for dehumidifying conditions.

Although some improvements are achieved by changing the fin and tube shapes and geometries, some more heat transfer performance enhancement can be obtained by placing different protrusions on the fin surface since these protrusions disturb the gas flow between fins and create vortices. However, the flow disturbance has also an adverse effect on pressure drop values of gas flows. So, the investigation of protrusions' effects also attracted many researches and the exploitation of the protrusions in heat exchangers has received a lot of attention. Most common types of protrusions investigated in the literature are winglet, wing, dimple (imprint), louver and wave type protrusions. Gentry and Jacobi [12] determined heat and mass transfer enhancement for a plate fin with the use of delta wing located at the leading edge, experimentally. Chen et al. [13] made a numerical analysis in order to explore the influence of delta winglet pairs which are punched in in-line arrangement on a fin and oval tube heat exchanger. Ligrani et al. [14] investigated a channel with a dimpled wall in a wind tunnel. They observed that the protrusion provides flow mixing. Wang et al. [15] conducted flow visualization observations for finand-tube heat exchangers with plain fin and fins having two different wave type vortex generators using dye-injection technique in a water tunnel. Mahmood and Ligrani [16] examined the flow and local Nusselt number distribution of a dimpled channel. Leu et al. [17] analyzed a three-row fin and tube heat exchanger with rectangular winglets in their numerical and experimental investigation. The best winglet span angle is found as $45^{\circ}$ in the study. Sommers and Jacobi [18] examined the effect of delta wing vortex generator on the performance of a heat exchanger operating under frosting and dry conditions. The results for dry operating conditions showed a $17-67 \%$ pressure drop increase with an increase in heat transfer. Pesteei et al. [19] accomplished an experimental study in order to determine the effects of delta winglet location. The delta winglet with constant geometrical dimensions and a $45^{\circ}$ angle of attack is placed at 5 different locations on the fin. It was found that the placement of delta winglet at downstream locations provides more heat transfer increase than the placement at upstream location. Allison and Dally [20] conducted flow visualization experiments using dye injection technique in a water tunnel in order to investigate the flow and vortex generation for flow up and flow down configurations of the winglet. They reported that the flow up configuration shows more promising flow characteristics as it directs the flow toward the tube. Lienhart et al. [21] investigated both numerically and experimentally the use of dimples in a turbulent channel flow. An increase in friction coefficient for the channel with one dimpled wall and the channel with two dimpled walls is observed compared to the channel with plane fins. $\mathrm{Wu}$ and Tao [22] investigated numerically the laminar flow in a rectangular channel which has a punched rectangular winglet pair on one of its walls. Their results indicated that the highest performance can be achieved when the winglets have a $45^{\circ}$ angle of attack. Wu and Tao [23] continued their numerical study and investigated the winglet pair effect for a laminar flow in a channel using the field synergy principle. Tian et al. [24] made numerical simulations investigating the effects of rectangular and delta winglet pairs placed on a flat plate channel laminar flow. Their findings revealed that both winglet types provide a significant Nusselt number increase accompanying high pressure drop values. Chu et al. [25] performed a numerical inquiry about the influence of delta winglet pairs on a fin and multi row oval tube heat exchanger. Downstream region is also found more efficient for the winglet and as the tube row number is decreased better heat transfer characteristics are encountered in their study. Bilir et al. [26] investigated the effects of three different protrusion types, winglet, imprint and balcony, on heat transfer and pressure drop performances of a fin and tube heat exchanger. First, the influence of each protrusion is examined separately. According to the results obtained, they examined two different fins with all three protrusion types, placed together on the fin surface. They found that all three protrusion types provide heat transfer enhancement along with a pressure drop increase compared to plate fin. Furthermore, the two fins with all three protrusions make an additional heat transfer increase compared to the fins with only one type protrusion.

As can be seen from the literature, there is a great effort made by many researchers in order to obtain more efficient heat exchangers by changing the geometrical parameters of plate fin, fin tube and by placing some types of vortex generators, which will disturb the fluid flow between the channel created by two fins, on the plate fin surface. However, it is also noticed that there is not any study in 
which the cumulative effects of different vortex generator types is analyzed, except the one which is made by the same authors of the present study [26]. The numerical investigation of the mentioned study is enlarged and some other parameters which were not taken into consideration are also included in the present study. In this study, the plate fin-tube heat exchanger of a commercially available domestic combi boiler apparatus is taken under consideration. The actual operating conditions of the mentioned apparatus are used throughout the numerical investigation. Firstly, the plate fin and tube geometry which will provide the best performance is determined by changing some fin and tube geometrical parameters within the geometrical dimension range used in actual applications. After the determination of the best plate fin and tube specification, the individual effect of each of the three different protrusion types (winglet, balcony, imprint) are analyzed separately. As a result, all geometrical specifications of the best fins with each protrusion type are determined separately. According to the results obtained from these analyses, ten different promising fins, containing all three different protrusions with the determined geometries, are decided to be investigated. Finally, the most efficient fin configuration with all three protrusions among the investigated cases is presented.

\section{Numerical simulation of the considered heat exchangers}

\subsection{Specifications of the heat exchanger under consideration and investigated parameters}

The heat exchanger consists of 101 plate fins with a fin width of $175 \mathrm{~mm}$ and fin pitch of $2.6 \mathrm{~mm}$. The thickness of the fins is $0.4 \mathrm{~mm}$. So, the tubecover, which is the extension of the fin which encloses the fin tube, is also $0.4 \mathrm{~mm}$ thick. These three values are kept constant in the numerical calculations as they are the ones used in practical application and several other parameters of the fins are changed in order to determine the optimum fin geometry of the finned tube gas to liquid heat exchanger. The dimensions of the reference fin, with which the study is started, are given in Fig. 1.

Because of the symmetrical conditions only one tenth segments of the actual fins are used in the numerical analyses. Thus, the schematic view of the investigated fins which are presented in Fig. 2 represent the one tenth segment of an actual fin with a width of $17.5 \mathrm{~mm}$.

Firstly, the following parameters about the plate fin geometry, which are illustrated in Fig. 2, are examined;

- Fin height $(L)$ and fin tube thickness $(t)$.

- Fin tube location $\left(L_{1}\right)$ and ellipticity $(b / a)$.

- Fin shape (wave height: $d$ ).

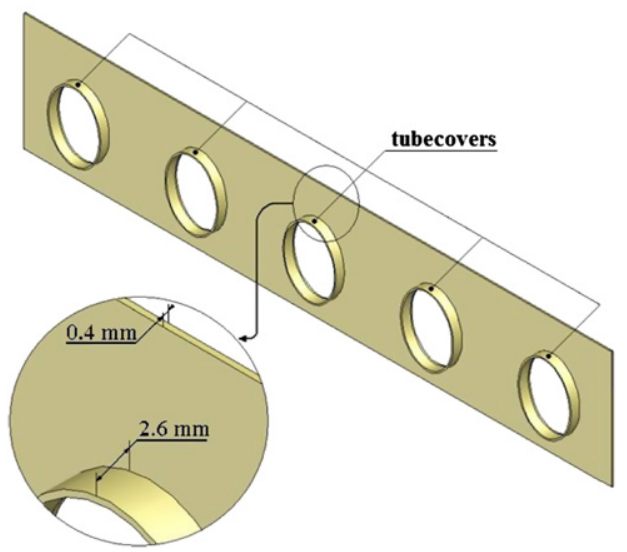

After the determination of the best plate fin geometrical dimensions, some protrusions, placed on the plate fin, are also investigated in order to reveal their effect on heat transfer between the flue gas (defined in section 2.3.2. of the present study) and heating water and pressure drop of the flue gas across the heat exchanger. The protrusions analyzed in this study are balcony, winglet and imprint type protrusions. Balcony type and imprint type protrusions are placed at the middle point between two fin tube centers while the winglet type protrusion is placed at the one third and two third of the distance between two fin tube centers. The parameters about the protrusions, which are illustrated in Fig. 2, can be summarized as follows:

- Protrusion height $(h)$, width $(w)$ and radius $(r)$.

For this part of the study the protrusion length is maintained as $2.425 \mathrm{~mm}$. The angle of attack for the winglets used in the present study is $\theta=45^{\circ}$.

- Protrusion length between two fins $\left(L_{\mathrm{b}}, L_{\mathrm{W}}, L_{\mathrm{i}}\right)$.

- Protrusion location on fin.

For the protrusion height, width and radius study and protrusion length between two fins study, the protrusions are always located at location 5 . However, in this part balcony and winglet type protrusions are placed at locations $1,2,3,4,5,6$ and 7 , while imprint type protrusion can only be placed at locations $2,3,4,5$ and 6 because of geometrical limitations. Location 1 coincides to the bottom point of tubecover, while location 3 and location 5 coincide with the fin tube center and tubecover upper point, respectively. Location 2 is at the middle point between locations 1 and 3. Similarly, location 4 is at the middle point between locations 3 and 5 . Location 6 is at the one third $(l / 3)$ while location 7 is at two third $(2 l / 3)$ of the distance between the upper point of tubecover and the upper point of the fin. Table 1 summarizes the steps of the investigation and the values used for each parameter.

\subsection{Numerical modeling}

Since the whole heat exchanger cannot be modeled numerically due to the computer source limitation, only the middle fin (the 51st fin) of the heat exchanger is taken into consideration. Furthermore, because of the symmetrical conditions, only one tenth segment of the actual fin is modeled and used in the numerical calculations. As a result, the model of a heat exchanger consists of two fin volumes with half fin thickness, a fin tube volume, a tubecover volume and a flue gas volume. The schematic view of the computational domain

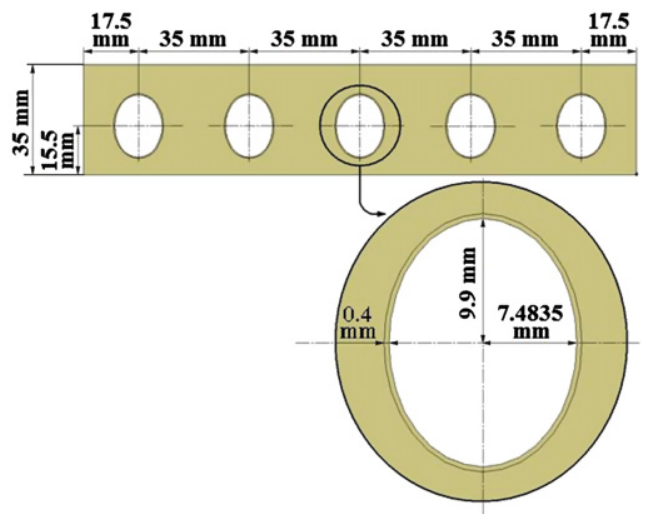

Fig. 1. The reference fin used in the heat exchanger and its dimensions. 
a

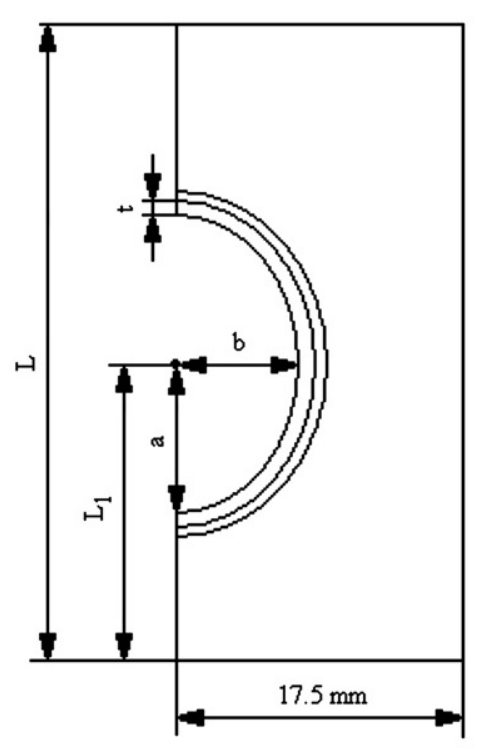

b

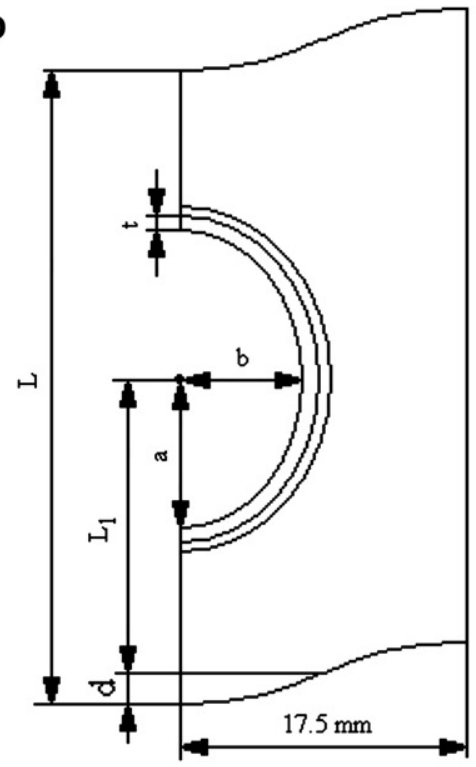

C

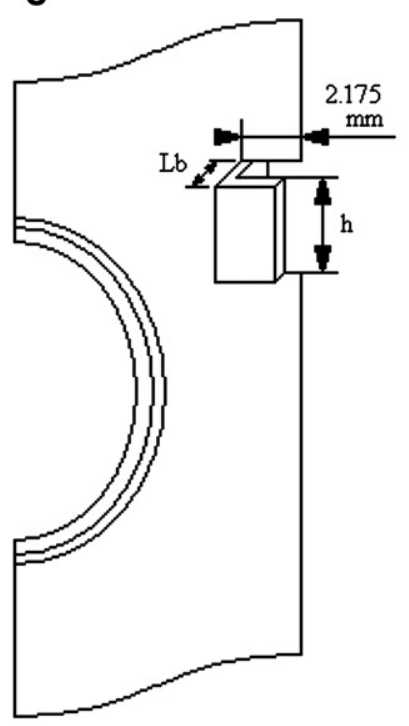

d

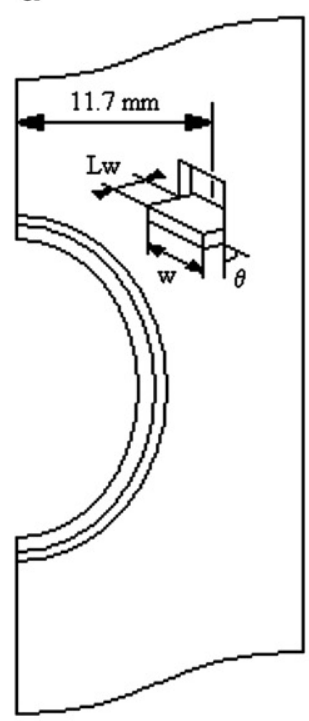

e

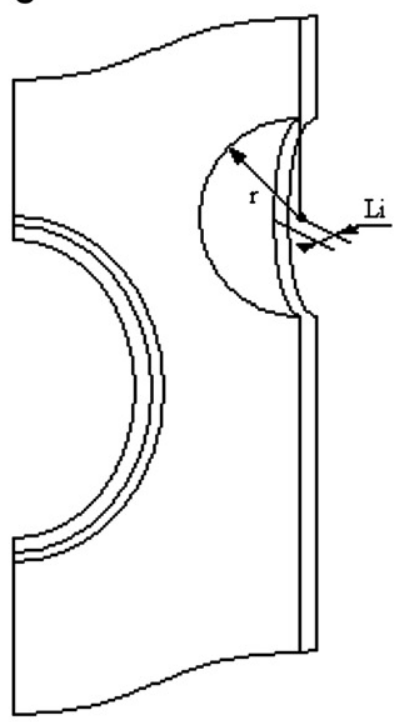

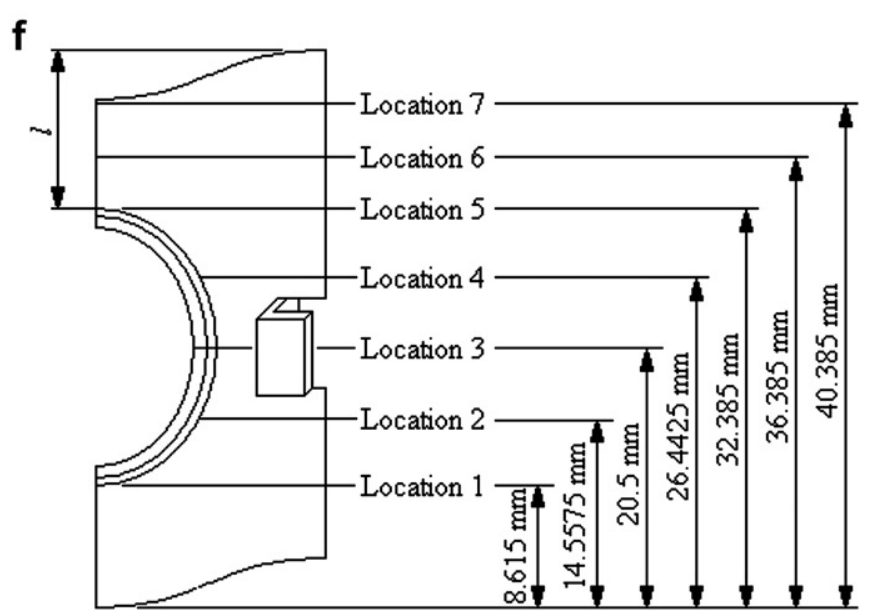

Fig. 2. Investigated parameters for (a) Rectangular plate fin (b) Wavy plate fin (c) Fin with balcony (d) Fin with winglet (e) Fin with imprint (f) Locations of protrusions. 
Table 1

Summary of the investigated parameters in the study.

\begin{tabular}{|c|c|c|c|c|}
\hline & $\begin{array}{l}\text { Step of the } \\
\text { investigation }\end{array}$ & Parameter name & $\begin{array}{l}\text { Parameter symbol } \\
\text { and unit }\end{array}$ & The variation of the parameter \\
\hline $\begin{array}{l}\text { Plate fin, fin tube dimension } \\
\text { and shape investigation }\end{array}$ & 1 & $\begin{array}{l}\text { Fin height } \\
\text { Fin tube thickness } \\
\text { Fin tube ellipticity } \\
\text { Fin tube location } \\
\text { Fin wave height }\end{array}$ & $\begin{array}{l}L(\mathrm{~mm}) \\
t(\mathrm{~mm}) \\
b / a \\
L_{1}(\mathrm{~mm}) \\
d(\mathrm{~mm})\end{array}$ & $\begin{array}{l}35,38 \text { and } 40 \\
0.6,0.8 \text { and } 1.2 \\
0.45,0.55,0.7345 \text { and } 1 \\
12.5,15.5,18.5 \text { and } 21.5 \\
1,2,3 \text { and } 5\end{array}$ \\
\hline $\begin{array}{l}\text { Protrusion dimension and } \\
\text { location investigation } \\
\text { (individual effects of the protrusions) }\end{array}$ & $\begin{array}{l}4 \\
5 \\
6 \\
7 \\
8 \\
9 \\
10\end{array}$ & $\begin{array}{l}\text { Balcony height } \\
\text { Winglet width } \\
\text { Imprint radius } \\
\text { Balcony length } \\
\text { Winglet length } \\
\text { Imprint length } \\
\text { Balcony location } \\
\text { Winglet location } \\
\text { Imprint location }\end{array}$ & $\begin{array}{l}h(\mathrm{~mm}) \\
w(\mathrm{~mm}) \\
r(\mathrm{~mm}) \\
L_{\mathrm{b}}(\mathrm{mm}) \\
L_{\mathrm{w}}(\mathrm{mm}) \\
L_{\mathrm{i}}(\mathrm{mm}) \\
\text { Location \# (locations are } \\
\text { illustrated in Fig. 2(f)) }\end{array}$ & $\begin{array}{l}2,3,4,6 \text { and } 8 \\
2,3,4,5 \text { and } 6 \\
4,5,6,7 \text { and } 8 \\
1,1.2,1.4,1.5,1.6,1.8,2,2.2 \text { and } 2.425 \\
1.3,1.4,1.6,1.8,2,2.2 \text { and } 2.425 \\
1.3,1.4,1.6,1.8,2,2.2 \text { and } 2.425 \\
1,2,3,4,5,6 \text { and } 7 \\
1,2,3,4,5,6 \text { and } 7 \\
2,3,4,5 \text { and } 6\end{array}$ \\
\hline Cumulative effects of the protrusions & 11 & $\begin{array}{l}\text { Use of three different } \\
\text { protrusions together }\end{array}$ & $\begin{array}{l}\text { Location \# (locations are } \\
\text { illustrated in Fig. } 2(\mathrm{f}) \text { ) }\end{array}$ & Summarized in Table 14 \\
\hline
\end{tabular}

simulating the heat exchanger is given in Fig. 3. The volume representing the flue gas which is passing through the gap between two fins is extended beyond the inlet and exit of the gap between two fins in order to enable more accurate boundary condition application.

Four hexahedral finite volume elements along the thickness of the half fin and twenty to twenty three (depending on the model geometry) of the same elements along the gap between two fins are used. Hexahedral meshes are generated for each heat exchanger model. As a result, up to 600,000 (approximately) hexahedral volume elements are generated for the heat exchanger models depending on the investigated geometry. The interval sizes used on faces are given in Fig. 4. Since the vicinity of fin tube and protrusions is subjected to higher gradients, finer meshes are employed for these regions.

In order to determine the mesh number to be used along the gap between two fins, numerical analysis of a heat exchanger with a plate fin is performed with different mesh numbers. It was found that the model, in which 20 elements along the gap between two fins are used, provides stable numerical solution in terms of heat transfer from the flue gas to the heating water and total pressure drop of flue gas across the heat exchanger as shown in Fig. 5.

It can be seen from Fig. 5 that the use of lower mesh numbers than 20 along the gap between two fins leads to inaccurate heat transfer and total pressure drop values. However, when the mesh number along this gap is increased beyond 20, it is observed that both heat transfer and total pressure drop values remain constant,

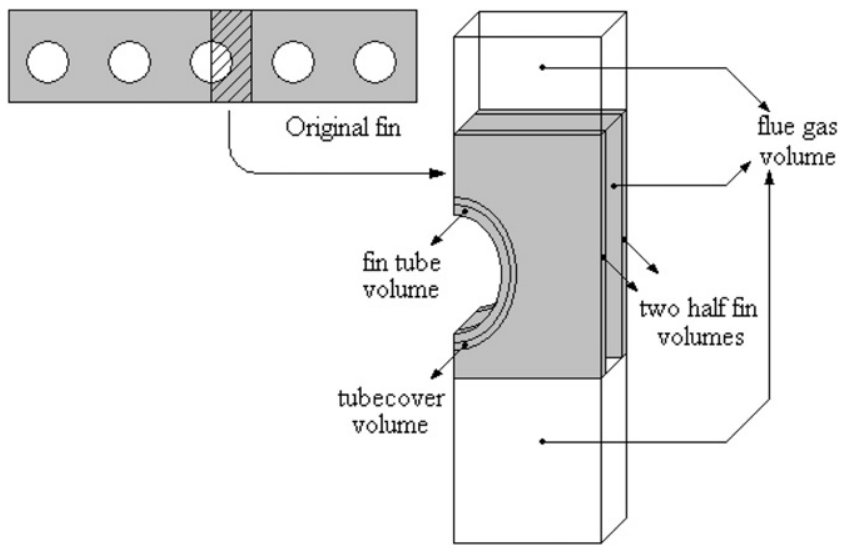

Fig. 3. Schematic view of the computational domain. which indicates that the use of 20 elements along the gap between two fins is appropriate to obtain realistic numerical solutions. Scaled residual values for velocity, continuity and energy equations are always found to be less than $10^{-7}, 10^{-4}$ and $10^{-7}$, respectively, for the converged numerical solutions of all investigated heat exchanger models.

\subsection{Boundary conditions, material properties and flow type}

\subsubsection{Boundary conditions}

The bottom surface of the heat exchanger models is the entrance of flue gas as shown in Fig. 4 and the flow is in $+Y$ direction. The inlet temperature ( $\left.T_{\text {flue gas }}\right)$ and the mass flow rate $\left(\dot{m}_{\text {flue gas }}\right)$ of the flue gas are defined as $1500 \mathrm{~K}$ and $1.904 \times 10^{-5} \mathrm{~kg} / \mathrm{s}$, respectively. These values are selected for the numerical analyses as they are used in an actual combi boiler apparatus application. The flue gas is exhausted from the top side of the heat exchanger after it passes through the gap between fins. So, outflow boundary condition is defined for the top side of the heat exchanger models. Symmetry boundary condition is applied to the side, front and back surfaces of the heat exchanger models, because of the presence of symmetry for these surfaces.

The heating water flows inside the fin tubes in the actual process. However in order not to model the heating water, convective heat transfer is defined for the fin tube inner wall. The convection coefficients between the water flowing inside the tubes and the fin tube inner wall $\left(h_{\text {water }}\right)$ are calculated according to the fin tube dimensions by using the Gnielinski correlation given by Eq. (1) [27].

$$
\mathrm{Nu}=\frac{(f / 2) \times(\mathrm{Re}-1000) \times \operatorname{Pr}}{1+12.7 \times(f / 2)^{1 / 2} \times\left(\mathrm{Pr}^{2 / 3}-1\right)}
$$

where,

$f=(1.58 \times \ln \operatorname{Re}-3.28)^{-2}$

Free stream temperature of water ( $\left.T_{\text {water }}\right)$ is also defined for the fin tube inner wall. The heating water enters the heat exchanger at $333 \mathrm{~K}$ and leaves at $353 \mathrm{~K}$ in the actual process. Since the $51 \mathrm{st}$ fin is taken into consideration and as the half of the third fin tube is used in the modeling of the heat exchangers, the free stream temperature of water is selected as $343 \mathrm{~K}$.

\subsubsection{Material properties}

The selected heat exchanger for the analyses is made of copper and constant thermophysical properties are selected as material 


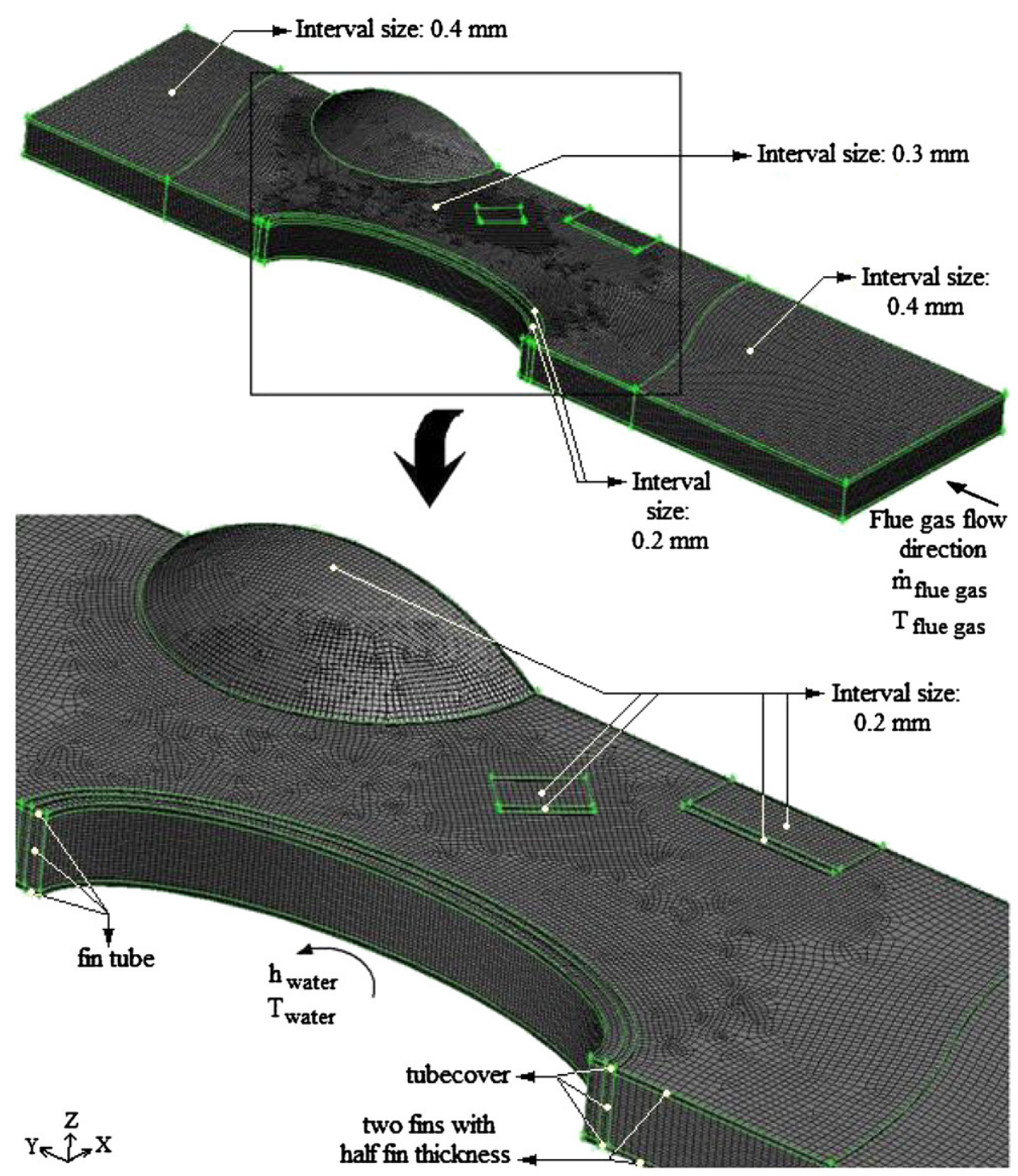

Fig. 4. Hexahedral finite volume elements created for heat exchanger models.

properties for all solid parts (fin, tubecover and fin tube) of the created numerical models.

Flue gas is the combustion products of the fuel burned in the burner of the combi boiler apparatus. The thermo physical properties of the flue gas used in the present study are also taken from the actual combi boiler apparatus application. Since the density value of the flue gas is not available, the density value of air is used instead. The inlet temperature of the flue gas is $1500 \mathrm{~K}$ and it was found that the exit temperature of flue gas at the outflow boundary is in the range of $400-500 \mathrm{~K}$. So, the density value for flue gas is taken as $0.3482 \mathrm{~kg} / \mathrm{m}^{3}$, which is the air density at $1000 \mathrm{~K}$ [28]. Polynomial expressions in terms of temperature for the specific heat, thermal conductivity and dynamic viscosity of flue gas are used in the numerical analyses.

\subsubsection{Type of flue gas flow}

The flow through the fins is assumed as laminar because of the small Reynolds number of the flow. Additionally, the flow is assumed as incompressible and steady.
In order to determine whether the flue gas flow is laminar or turbulent, the Reynolds number of the flow is calculated as follows [28];

$\operatorname{Re}=\frac{\rho V D_{\mathrm{h}}}{\mu}$

Since the fins form small channels for the flue gas flow, the hydraulic diameter of these channels should be calculated in order to determine the Reynols number [28].

$D_{\mathrm{h}}=\frac{4 \times A}{P}$

Since the fin width is $175 \mathrm{~mm}$ and the fin pitch is $2.6 \mathrm{~mm}$, the cross sectional area $(A)$ and the perimeter of the channel $(P)$ are calculated as $4.55 \times 10^{-4} \mathrm{~m}^{2}$ and $0.3552 \mathrm{~m}$, respectively. As a result, the hydraulic diameter for a channel formed by two fins is found as $5.1239 \times 10^{-3} \mathrm{~m}$. The dynamic viscosity of flue gas is taken as $4.119 \times 10^{-5} \mathrm{~kg} / \mathrm{ms}$, which is calculated from the polynomial equation considered for the flue gas at $1000 \mathrm{~K}$, which is the approximate average of the flue gas inlet and exit temperatures for 

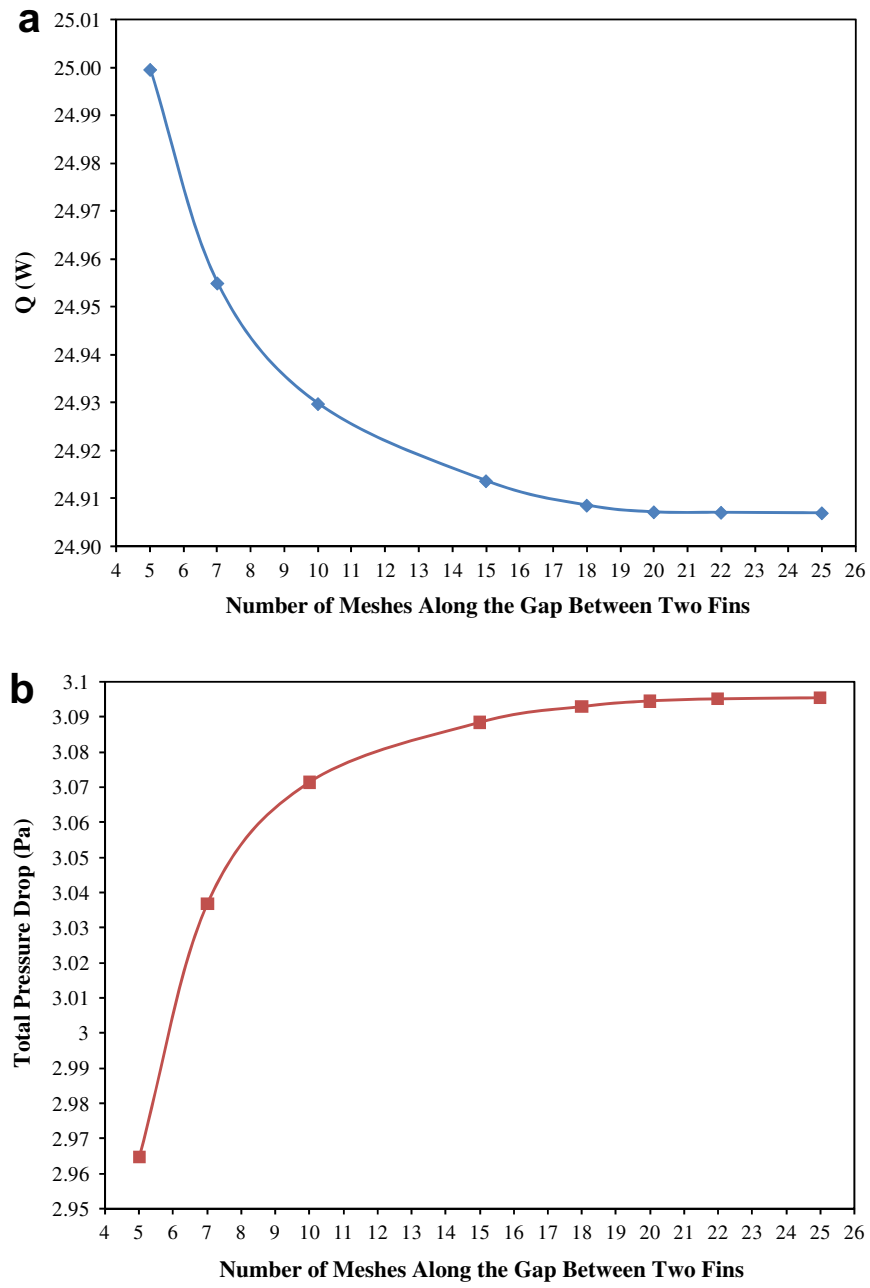

Fig. 5. The effect of finite volume element number along the gap between two fins. (a) On heat transfer rate. (b) On total pressure drop across the heat exchanger.

the investigated heat exchangers. The velocity of flue gas is selected as $3.85 \mathrm{~m} / \mathrm{s}$, which is the highest velocity value encountered inside the channel formed by two fins. The maximum Reynolds number that can be obtained for the investigated cases is calculated from Eq. (2) as 166.76, which is smaller than the critical value of the transition to the turbulent flow $(\operatorname{Re}=2300)$ for the channel flows. So, it is concluded that the flue gas flow can be accepted as laminar.

\section{Verification of the numerical models used in the present study}

The numerical investigation of various parameters is accomplished in the present study using the computational fluid dynamics software, "Fluent". Since the fins considered by other researchers differ from the ones investigated in the present study, it was not possible to compare directly the numerical results found for the investigated cases with numerical and experimental results given by other authors. For this reason, the fins used in a similar study [23], in which the effects of a winglet pair on heat transfer are investigated numerically and experimentally, are analyzed numerically in order to accomplish validation of the current study.

In the experimental part of the mentioned study [23], aluminum fins with a length of $400 \mathrm{~mm}$ are tested in a thermally isolated wind tunnel for different air velocity values. The winglet dimensions are $60 \mathrm{~mm}$ length and $27 \mathrm{~mm}$ height. A $0.15 \mathrm{~mm}$ thick electrical heating element is placed between two aluminum plates, each with a $1 \mathrm{~mm}$ thickness. The total heating power dissipated by the heating film is $35 \mathrm{~W}$. The experimental average convective heat transfer coefficients over the upper and lower fin surfaces $(h)$ are determined and additionally computational results for $\mathrm{h}$ for the investigated fins are presented in [23]. The fin with a $45^{\circ}$ angle of attack is modeled for the comparison, because this is the winglet angle of attack value for the investigated fins in the present study. Half of the fin and test channel is taken as computational domain as seen in Fig. 6(a) since there is symmetry. An inner heat source is given for the heating film volume in the numerical models. The inner heat source value is taken as $7,291,667 \mathrm{~W} / \mathrm{m}^{3}$ for plate fin and $7,481,030 \mathrm{~W} / \mathrm{m}^{3}$ for the fin with winglet. The difference between the source values results from the presence of the punched winglet hole in the model with a winglet, which changes also the volume of the heating film.

$1,200,000$ control volume elements for plate fin and $1,760,000$ control volume elements for the fin with winglet are created for the models to be used in comparison. Although the total control volume element number used in the present study (up to 600,000 elements) seems to be lower than that of the models used in comparison, the geometrical dimensions of the models used in comparison are also much greater than those of the models used in the numerical investigation of the present study. Additionally the wind tunnel channel dimensions investigated in [23] are also noticeably greater than the distance between the fins $(2.6 \mathrm{~mm})$ and the width of one tenth fin segment $(17.5 \mathrm{~mm})$ investigated in this study. Thus, it can be easily said that the mesh quality of the models investigated in the present study is significantly finer.

It can be seen from Fig. 7(a) and (b) that the computational and experimental results of [23] and the numerical results of the present study are very close. The difference between the experimental results of [23] and the numerical results of the present study raises from the number of meshes used for the numerical models, which is limited due to the available computer capacity, and some numerical errors such as round-off error. However, it can be observed from Fig. 7(b) that the numerical results of the present

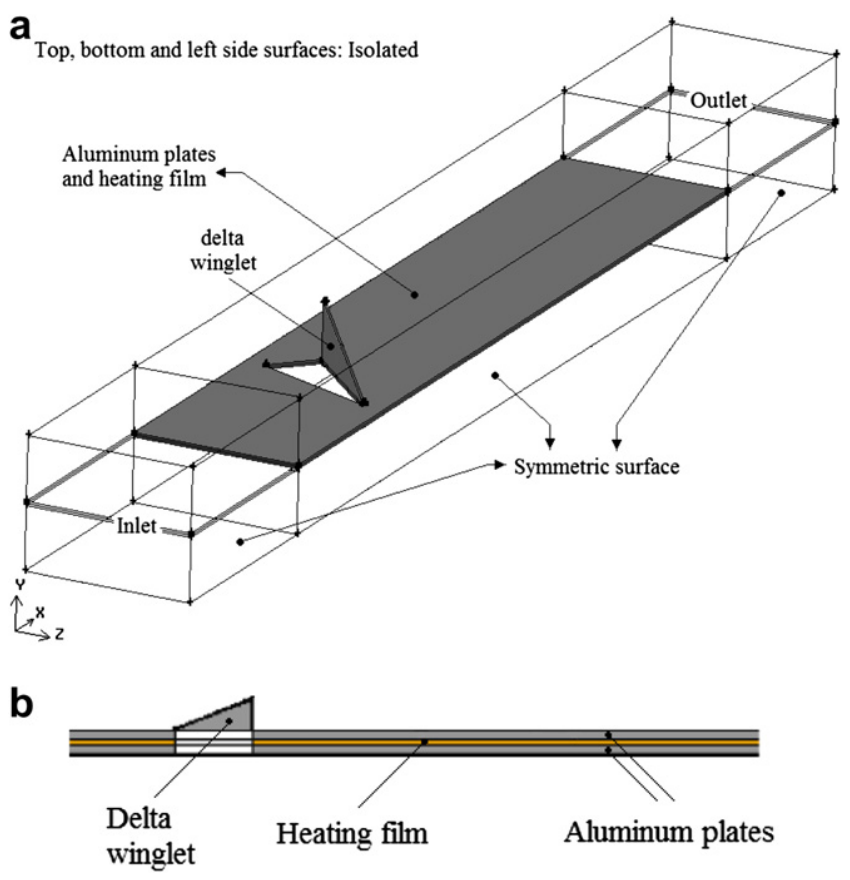

Fig. 6. (a) The computational model created for the comparison with the computational and experimental study of [23]. (b) Cross section of the fin investigated in [23]. 

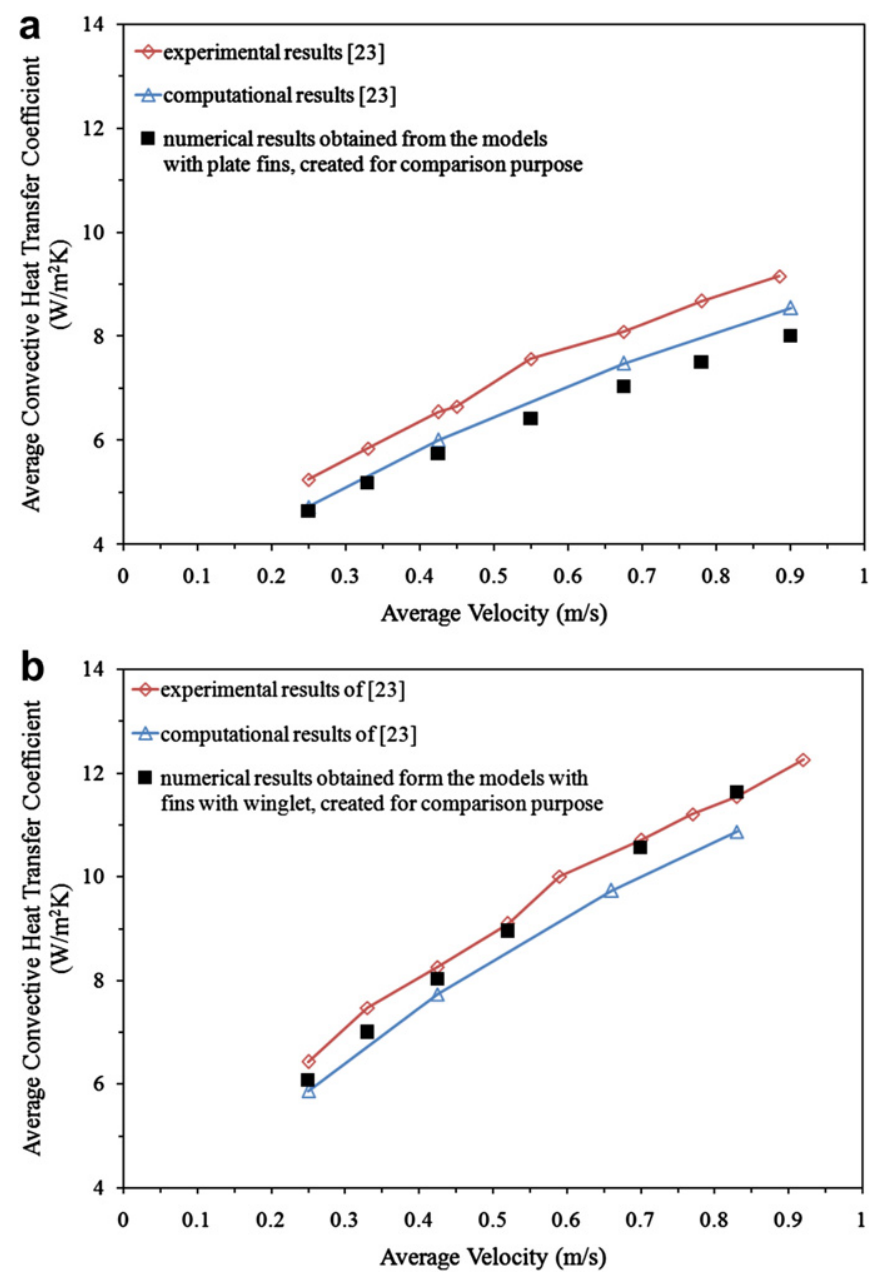

Fig. 7. Comparison of the computational and experimental results of [23] with the numerical results obtained from, (a) the models with plate fins (b) the models with fins with a winglet having a $45^{\circ}$ angle of attack.

study are even more realistic and more consistent with the experimental results of [23] for the fin with winglet case. The agreement between the results of the present study and the results of [23] ensures the reliability of the numerical models used in the analysis of several different fin and protrusion parameters, because finer finite control volume elements are used in the mentioned numerical models, and the use of coarser control volume elements are proved to give reasonable results.

\section{Results and discussion}

The optimization study is started with the investigation of the parameters about the plate fin and circular/elliptical tubes. First, the reference fin with the dimensions given in Fig. 1 is taken into consideration and the fin height and fin tube thickness values are varied. After the determination of the best values for the mentioned parameters, the second step is to examine the effects of fin tube location and ellipticity. Last parameter to be observed for the plate fin is the shape of the fin. In this step the waviness value $(d)$ of the fin is changed and finally the best plate fin geometry is established. The optimization study for the protrusions starts as the next step and the first parameters are the balcony height, winglet width and imprint radius values. Secondly, the length of three different protrusions in the gap between two fins is varied and the optimum parameters about the three different protrusions are ascertained.
Final step about the protrusions is to differ the protrusion location on the fin surface. Hence the best protrusion geometry and location for these three protrusions are determined separately. As the final step of the study, 10 different fins with all three protrusions are created by taking the results obtained up to this point into consideration. The best one among these ten fins is determined and the optimization process is ended.

\subsection{The effect of fin height and fin tube thickness}

The fin height $(L)$ is varied between $35 \mathrm{~mm}$ and $40 \mathrm{~mm}$ while the ellipticity of the fin tube $(b / a)$ and location of fin tube $\left(L_{1}\right)$ are kept constant at 0.7345 and $15.5 \mathrm{~mm}$, respectively. In addition, the fin tube thickness value is also changed between $0.6 \mathrm{~mm}$ and $1.2 \mathrm{~mm}$ while the other parameters are constant. The schematic view of a plate fin and the investigated parameters are illustrated in Fig. 2(a). The dimensions of the examined plate fins are given in Table 2 as well.

The transferred heat from the flue gas to the heating water passing through the fin tube and the flue gas total pressure drop are calculated numerically using Fluent software and the numerical results are presented in Table 2 . Normalized heat transfer and total pressure drop values are also presented by taking the values of the model P-35 mm- $-0.8 \mathrm{~mm}$ as $100 \%$ in order to enable the comparison of the fins easier. The geometry of this fin is taken from the reference fin.

It can be seen from the results of this part of the study that the model P-40mm- $0.8 \mathrm{~mm}$ with a fin height of $40 \mathrm{~mm}$ is the best fin in terms of heat transfer performance, as expected. The higher fin heat transfer surface area of the model P-40mm$0.8 \mathrm{~mm}$ provides the highest heat transfer rate from the flue gas to the heating water. It is also seen that the model P-40mm$0.8 \mathrm{~mm}$ does not create an excessive pressure drop value when compared with the model P-35mm-0.8mm with a fin height value of $35 \mathrm{~mm}$. Another conclusion of this part of the study is that the heat transfer and pressure drop performance of the fin with a thinnest fin tube (P-35mm-0.6mm), which has a $0.6 \mathrm{~mm}$ thick fin tube is the best compared to the fins $\mathrm{P}-35 \mathrm{~mm}-0.8 \mathrm{~mm}$ with a $0.8 \mathrm{~mm}$ thick fin tube and P-35mm-1.2mm with a $1.2 \mathrm{~mm}$ thick fin tube. The block effect of the fin tube and tubecover on the flue gas flow reduces when the fin tube thickness is decreased. Therefore, lower total pressure drop is created when the fin tube thickness is thinner.

As a result of these conclusions, it is decided to continue the optimization study with a plate fin with a fin height value of $40 \mathrm{~mm}$ and a fin tube thickness value of $0.6 \mathrm{~mm}$.

\subsection{The effect of fin tube location and ellipticity}

In order to determine the optimum fin tube shape and location, 16 different fins are investigated in this section of the study. These fins are grouped in 4 different types according to their fin tube

Table 2

Fin height, fin tube thickness values and heat transfer, total pressure drop values of the investigated plate fins.

\begin{tabular}{lllllll}
\hline Model name & $\begin{array}{l}L \\
(\mathrm{~mm})\end{array}$ & $\begin{array}{l}t \\
(\mathrm{~mm})\end{array}$ & $\begin{array}{l}Q \text { (per } \\
\text { segment) } \\
(\mathrm{W})\end{array}$ & $\begin{array}{l}\text { Normalized } \\
Q(\%)\end{array}$ & $\begin{array}{l}\text { Total } \\
\text { pressure } \\
\text { drop (Pa) }\end{array}$ & $\begin{array}{l}\text { Normalized } \\
\text { total pressure } \\
\text { drop (\%) }\end{array}$ \\
\hline P-35mm-0.8mm 35 & 0.8 & 24.0611 & 100 & 3.3649 & 100 \\
P-35mm-0.6mm 35 & 0.6 & 24.1179 & 100.236 & 3.2894 & 97.756 \\
P-35mm-1.2mm 35 & 1.2 & 23.9364 & 99.482 & 3.5294 & 104.889 \\
P-38mm-0.8mm 38 & 0.8 & 24.3960 & 101.392 & 3.5024 & 104.086 \\
P-40mm-0.8mm 40 & 0.8 & 24.5797 & 102.155 & 3.5915 & 106.734 \\
\hline
\end{tabular}


Table 3

Dimensions of the fin tubes with different ellipticity values.

\begin{tabular}{lcl}
\hline Fin tube ellipticity $(b / a)$ & $a$ & $b$ \\
\hline 1 & 7.9 & 7.9 \\
0.7345 & 9.1 & 6.6835 \\
0.55 & 10.183 & 5.6 \\
0.45 & 10.885 & 4.9 \\
\hline
\end{tabular}

ellipticity $(b / a)$. One group consists of the fins with cylindrical fin tubes $(b / a=1)$ while the other three groups have elliptical fin tubes. In this part the fin height and fin tube thickness values are taken constant as $40 \mathrm{~mm}$ and $0.6 \mathrm{~mm}$, respectively.

The same heat transfer area between the tubecover outer surface and flue gas flow is assured by keeping the outer perimeter of tubecover as constant while determining the dimensions of fin tubes with different ellipticity values. As a result the dimensions given in Table 3 are calculated.

The velocity of water flow inside the fin tube is different for 4 different fin tubes since the mass flow rate of water is taken as constant and the cross sectional area of the fin tube is different for each type. So, the convective heat transfer coefficient, which will be the boundary condition for the numerical models, will differ for each group with different fin tube ellipticity values. The convective heat transfer coefficient is calculated using Eq. (1) and the following results are found for each group;

- For the fin tubes with ellipticity value of $1 ; h_{\mathrm{water}}=9870 \mathrm{~W} /$ $\mathrm{m}^{2} \mathrm{~K}$.

- For the fin tubes with ellipticity value of $0.7345 ; h_{\text {water }}=10,000$ $\mathrm{W} / \mathrm{m}^{2} \mathrm{~K}$.

- For the fin tubes with ellipticity value of $0.55 ; h_{\text {water }}=10,800$ $\mathrm{W} / \mathrm{m}^{2} \mathrm{~K}$.

- For the fin tubes with ellipticity value of $0.45 ; h_{\text {water }}=11,550$ $\mathrm{W} / \mathrm{m}^{2} \mathrm{~K}$.

Four different fin tube locations $\left(L_{1}\right)$ are investigated for each group. These locations are defined as $12.5 \mathrm{~mm}, 15.5 \mathrm{~mm}, 18.5 \mathrm{~mm}$ and $21.5 \mathrm{~mm}$ away from the bottom point of fin. The dimensions used in this section are tabulated in Table 4.

The numerical results of heat transfer and pressure drop values for the plate fins with different ellipticity values are tabulated in Table 4 . In this section, the normalized heat transfer and total pressure drop values are calculated by assuming the values of the model c- $12.5 \mathrm{~mm}$ as $100 \%$.
It can be observed from Table 4 that as the ellipticity value of the fin tube is decreased (as more elliptical tube is used), the heat transferred across the heat exchanger increases. The increased ellipticity also affects pressure drop positively. This result stems from the increase in cross section of flue gas flow when more elliptical fin tube is used. Elliptical tube results less drag than the circular tube due to its better aerodynamic shape. This shape also causes better heat transfer characteristics.

The second outcome is that when the fin tube is placed in downstream region, there is an increase in heat transfer while the flue gas total pressure drop decreases. These results are consistent with the findings given in the studies of Kim and Song [5] and Erek et al. [6]. However, the enhancement in heat transfer is found to be valid up to a certain value. It is seen that the best fin tube position is at a distance of $18.5 \mathrm{~mm}$ away from the bottom of the fin since maximum heat transfer value is obtained at this location. For these reasons, it is decided to continue the study with a fin having a fin tube with ellipticity value of 0.45 and the location of fin tube is chosen at $18.5 \mathrm{~mm}$ away from the bottom point of the fin according to the results (e0.45-18.5 mm).

\subsection{The effect of fin shape}

In this part of the study, wavy fins are investigated. However, the wavy fin definition used for corrugated fins does not define the fins under consideration in this study. The present wavy fins investigated in the analyses are also plate fins. However their upper and bottom parts are in wavy shape as illustrated in Fig. 2(b). The fin heat transfer surface of wavy fins is kept the same as the plate fins in order to make the comparison between two fin types possible.

The wave height $(d)$ is changed between $1 \mathrm{~mm}$ and $5 \mathrm{~mm}$. Four different wave height values, namely $1,2,3$ and $5 \mathrm{~mm}$, are investigated. The dimensions of the fin e $0.45-18.5 \mathrm{~mm}$ are kept constant except the wave height value in this part of the study and the values used are summarized in Table 5 along with the model names.

In order to compare the wavy fins with plate fins, the values of the plate fin with the same geometrical dimensions (e0.45-18.5 mm) are taken as $100 \%$ and normalized values of heat transfer and total pressure drop values are calculated with this assumption. The calculated heat transfer and total pressure drop values are also tabulated in Table 5.

As can be seen from Table 5, the use of wavy fins can be beneficial in some cases. It is also observed that as the wave height is increased, the total pressure drop decreases. The models with

Table 4

Fin tube location, ellipticity values and heat transfer, total pressure drop values of the investigated plate fins.

\begin{tabular}{|c|c|c|c|c|c|c|c|}
\hline & Model name & $\begin{array}{l}L_{1} \\
(\mathrm{~mm})\end{array}$ & $\begin{array}{l}\text { Ellipticity } \\
(b / a)\end{array}$ & $\begin{array}{l}Q(\text { per } \\
\text { segment) }(W)\end{array}$ & $\begin{array}{l}\text { Normalized } \\
Q(\%)\end{array}$ & $\begin{array}{l}\text { Total pressure } \\
\text { drop }(\mathrm{Pa})\end{array}$ & $\begin{array}{l}\text { Normalized total } \\
\text { pressure drop (\%) }\end{array}$ \\
\hline \multirow[t]{4}{*}{ Type 1} & $\mathrm{c}-12.5 \mathrm{~mm}$ & 12.5 & 1 & 24.3610 & 100.000 & 3.9502 & 100.000 \\
\hline & $\mathrm{c}-15.5 \mathrm{~mm}$ & 15.5 & 1 & 24.4242 & 100.259 & 3.9015 & 98.767 \\
\hline & $\mathrm{c}-18.5 \mathrm{~mm}$ & 18.5 & 1 & 24.4551 & 100.386 & 3.8706 & 97.985 \\
\hline & $\mathrm{c}-21.5 \mathrm{~mm}$ & 21.5 & 1 & 24.4540 & 100.382 & 3.8489 & 97.436 \\
\hline \multirow[t]{4}{*}{ Type 2} & $\mathrm{e} 0.7345-12.5 \mathrm{~mm}$ & 12.5 & 0.7345 & 24.5508 & 100.779 & 3.5625 & 90.185 \\
\hline & $\mathrm{e} 0.7345-15.5 \mathrm{~mm}$ & 15.5 & 0.7345 & 24.6187 & 101.058 & 3.5165 & 89.021 \\
\hline & $\mathrm{e} 0.7345-18.5 \mathrm{~mm}$ & 18.5 & 0.7345 & 24.6425 & 101.156 & 3.4897 & 88.342 \\
\hline & $\mathrm{e} 0.7345-21.5 \mathrm{~mm}$ & 21.5 & 0.7345 & 24.6235 & 101.078 & 3.4793 & 88.079 \\
\hline \multirow[t]{4}{*}{ Type 3} & e0.55-12.5mm & 12.5 & 0.55 & 24.7073 & 101.422 & 3.3023 & 83.598 \\
\hline & e0.55-15.5mm & 15.5 & 0.55 & 24.7858 & 101.744 & 3.2598 & 82.522 \\
\hline & e0.55-18.5mm & 18.5 & 0.55 & 24.8082 & 101.836 & 3.2351 & 81.897 \\
\hline & $\mathrm{e} 0.55-21.5 \mathrm{~mm}$ & 21.5 & 0.55 & 24.7907 & 101.764 & 3.2280 & 81.717 \\
\hline \multirow[t]{4}{*}{ Type 4} & e0.45-12.5mm & 12.5 & 0.45 & 24.8047 & 101.821 & 3.1573 & 79.928 \\
\hline & e0.45-15.5mm & 15.5 & 0.45 & 24.8825 & 102.141 & 3.1172 & 78.912 \\
\hline & e0.45-18.5mm & 18.5 & 0.45 & 24.9072 & 102.242 & 3.0939 & 78.323 \\
\hline & $\mathrm{e} 0.45-21.5 \mathrm{~mm}$ & 21.5 & 0.45 & 24.8889 & 102.167 & 3.0883 & 78.181 \\
\hline
\end{tabular}


Table 5

Wave height values and heat transfer, total pressure drop values of the investigated wavy fins.

\begin{tabular}{llllll}
\hline Model name & $\begin{array}{l}d \\
(\mathrm{~mm})\end{array}$ & $\begin{array}{l}Q \text { (per } \\
\text { segment) } \\
(\mathrm{W})\end{array}$ & $\begin{array}{l}\text { Normalized } \\
Q(\%)\end{array}$ & $\begin{array}{l}\text { Total pressure } \\
\text { drop (Pa) }\end{array}$ & $\begin{array}{l}\text { Normalized } \\
\text { total pressure } \\
\text { drop (\%) }\end{array}$ \\
\hline e-0.45-18.5mm & 0 & 24.9072 & 100.000 & 3.0939 & 100.000 \\
wavy-d1mm & 1 & 24.9126 & 100.022 & 3.0930 & 99.971 \\
wavy-d2mm & 2 & 24.9176 & 100.042 & 3.0816 & 99.602 \\
wavy-d3mm & 3 & 24.9019 & 99.979 & 3.0631 & 99.004 \\
wavy-d5mm & 5 & 24.8530 & 99.782 & 3.0053 & 97.136 \\
\hline
\end{tabular}

a wave height of $1 \mathrm{~mm}$ and $2 \mathrm{~mm}$ show slightly better heat transfer performance compared to the plate fin. Furthermore, the wavy fin with a $2 \mathrm{~mm}$ wave value is better than the one with a $1 \mathrm{~mm}$ wave value. So, in the following sections of the study, it is decided to use the model wavy- $\mathrm{d} 2 \mathrm{~mm}$ for the fin optimization.

\subsection{The effect of protrusion dimensions}

After the determination of the best plate fin as wavy-d2mm, three different protrusions which are placed on the plate fin surface are taken into consideration. These protrusions disturb the flow and thus create a certain amount of heat transfer enhancement. However, since they block the flue gas flow passing through the gaps between fins, they also cause some pressure drop increase. In the present study, balcony, imprint and winglet type protrusions are investigated.

\subsubsection{The effect of balcony type protrusion height}

Firstly, the use of balcony type protrusion is focused on. The balcony type protrusion height $(h)$ is varied between $2 \mathrm{~mm}$ and $8 \mathrm{~mm}$ while all the other dimensions are kept constant. The dimensions in Fig 2(c) are the same as those of the model wavy$\mathrm{d} 2 \mathrm{~mm}$, which is determined as the best plate fin in the previous parts of the investigation and the balcony length $\left(L_{\mathrm{b}}\right)$ is maintained as $2.425 \mathrm{~mm}$. The balcony heights used in the present part of the study are tabulated in Table 6 .

In order to reveal the effect of balcony type protrusion usage, the results of plate fin with the same dimensions (wavy-d2mm) are also presented in Table 6 . The results of the fin wavy- $\mathrm{d} 2 \mathrm{~mm}$ are assumed to be $100 \%$ in order to obtain normalized heat transfer and total pressure drop values.

It is observed from Table 6 that the heat transfer performance improves up to a balcony height value of $3 \mathrm{~mm}$ and after this value a decreasing trend is observed. However, the total pressure drop value increases as the balcony height value is increased. The reason of heat transfer enhancement due to the use of balcony type protrusion is the fact that the balcony type protrusion disturbs the flow and directs the flow to the fin tube. Nevertheless, since the balcony form an obstacle against the fluid flow, the total pressure drop values of the fins with balcony type protrusion are higher than the one of the corresponding plate fin.

Table 6

Balcony height values and heat transfer, total pressure drop values of the investigated fins.

\begin{tabular}{llllll}
\hline Model name & $\begin{array}{l}h \\
(\mathrm{~mm})\end{array}$ & $\begin{array}{l}Q \text { (per } \\
\text { segment) } \\
(\mathrm{W})\end{array}$ & $\begin{array}{l}\text { Normalized } \\
Q(\%)\end{array}$ & $\begin{array}{l}\text { Total pressure } \\
\text { drop (Pa) }\end{array}$ & $\begin{array}{l}\text { Normalized } \\
\text { total pressure } \\
\text { drop (\%) }\end{array}$ \\
\hline wavy-d2mm & 0 & 24.9176 & 100 & 3.0816 & 100 \\
Bh-2mm & 2 & 24.9703 & 100.211 & 3.1980 & 103.777 \\
Bh-3mm & 3 & 24.9717 & 100.217 & 3.2108 & 104.193 \\
Bh-4mm & 4 & 24.9689 & 100.206 & 3.2225 & 104.572 \\
Bh-6mm & 6 & 24.9639 & 100.186 & 3.2440 & 105.270 \\
Bh-8mm & 8 & 24.9587 & 100.165 & 3.2643 & 105.929 \\
\hline
\end{tabular}

As a result of this part of the study, it is found that the fin with a balcony height of $3 \mathrm{~mm}(\mathrm{Bh}-3 \mathrm{~mm})$ gives the best heat transfer performance. It can be also seen that the total pressure drop value increase due to the usage of balcony type protrusion does not reach an excessive value. So, it is decided to use the balcony dimensions of the model Bh-3mm in the next parts of the study.

\subsubsection{The effect of winglet type protrusion width}

Similar to the balcony type protrusion, winglet type protrusion is also investigated in this study. The width of the winglet $(w)$ is changed between $2 \mathrm{~mm}$ and $6 \mathrm{~mm}$. The dimensions of the fins with winglet type protrusion are tabulated in Table 7. The dimensions in Fig. 2(d), other than winglet length in the gap between two fins $\left(L_{\mathrm{W}}\right.$, which is maintained at $2.425 \mathrm{~mm}$ ) and winglet width $(w)$, are again the same as those of the plate fin wavy-d2mm. Similar to the previous part of the study, the numerical results of the fins with winglets are compared with the plate fin wavy-d2mm, whose values are assumed to be $100 \%$, in Table 7 .

The heat transfer rate of the fins with winglets is observed to be increased until the winglet width reaches $3 \mathrm{~mm}$. Increasing the winglet width beyond this value leads to a lower heat transfer rate. It is also seen that wider winglets causes higher total pressure drop.

The winglet directs the flow into the wake region of the tube. The mixing of the flue gas as it passes through the winglet and the resulting vortices creates an enhancement in heat transfer. However, higher total pressure drop values are also encountered due to the block effect created by the winglets on the flow.

As the result of this part of the study, it is decided to continue the next parts using the winglet dimensions of the fin $\mathrm{Ww}-3 \mathrm{~mm}$ because of its highest heat transfer rate and modest total pressure drop increase.

\subsubsection{The effect of imprint type protrusion radius}

The effect of the imprint type protrusion radius is also investigated as a final part of this section of the study. The radius value is varied between $4 \mathrm{~mm}$ and $8 \mathrm{~mm}$. All dimensions shown in Fig. 2(e) (except the radius of the imprint $(r)$ and imprint length $\left(L_{\mathrm{i}}\right)$, which is taken as $2.425 \mathrm{~mm}$ ) are kept the same as those of the plate fin wavy- $\mathrm{d} 2 \mathrm{~mm}$. Similar to the previous two parts of the study, the values of the corresponding plate fin wavy- $\mathrm{d} 2 \mathrm{~mm}$ are taken as $100 \%$ in order to make the comparison of the fins easier. The summary of the geometry and heat transfer and total pressure drop values of the models investigated in this part is given in Table 8 .

The heat transfer enhancement increases as the radius of imprint increases up to $7 \mathrm{~mm}$. The imprint also directs the flow into the fin tube and results in an enhancement in heat transfer. The total pressure drop value of the fins with imprint shows an increasing trend up to a radius value of $5 \mathrm{~mm}$, after this value it starts to decrease. The reason of this pressure drop decrease can be explained with the fact that as the imprint radius value is decreased, more concave structure is obtained for the imprint. The concavity of the imprint leads to an increase in pressure drop penalty.

Table 7

Winglet width values and heat transfer, total pressure drop values of the investigated fins.

\begin{tabular}{llllll}
\hline Model name & $\begin{array}{l}w \\
(\mathrm{~mm})\end{array}$ & $\begin{array}{l}Q \text { (per } \\
\text { segment) } \\
(\mathrm{W})\end{array}$ & $\begin{array}{l}\text { Normalized } \\
Q(\%)\end{array}$ & $\begin{array}{l}\text { Total pressure } \\
\text { drop (Pa) }\end{array}$ & $\begin{array}{l}\text { Normalized } \\
\text { total pressure } \\
\text { drop (\%) }\end{array}$ \\
\hline wavy-d2mm & 0 & 24.9176 & 100 & 3.0816 & 100 \\
Ww-2mm & 2 & 24.9674 & 100.200 & 3.2369 & 105.040 \\
Ww-3mm & 3 & 24.9686 & 100.205 & 3.3000 & 107.087 \\
Ww-4mm & 4 & 24.9528 & 100.141 & 3.3726 & 109.443 \\
Ww-5mm & 5 & 24.9399 & 100.089 & 3.4549 & 112.114 \\
Ww-6mm & 6 & 24.9253 & 100.031 & 3.5483 & 115.145 \\
\hline
\end{tabular}


Table 8

Imprint radii values and heat transfer, total pressure drop values of the investigated fins.

\begin{tabular}{llllll}
\hline Model name & $\begin{array}{l}r \\
(\mathrm{~mm})\end{array}$ & $\begin{array}{l}Q \text { (per } \\
\text { segment) } \\
(\mathrm{W})\end{array}$ & $\begin{array}{l}\text { Normalized } \\
Q(\%)\end{array}$ & $\begin{array}{l}\text { Total pressure } \\
\text { drop (Pa) }\end{array}$ & $\begin{array}{l}\text { Normalized } \\
\text { total pressure } \\
\text { drop (\%) }\end{array}$ \\
\hline wavy-d2mm & 0 & 24.9176 & 100 & 3.0816 & 100 \\
Ir-4mm & 4 & 24.9982 & 100.323 & 3.2716 & 106.166 \\
Ir-5mm & 5 & 25.0210 & 100.415 & 3.2721 & 106.182 \\
Ir-6mm & 6 & 25.0403 & 100.492 & 3.2715 & 106.162 \\
Ir-7mm & 7 & 25.0476 & 100.522 & 3.2707 & 106.136 \\
Ir-8mm & 8 & 25.0442 & 100.508 & 3.2703 & 106.123 \\
\hline
\end{tabular}

According to the numerical results of this part of the study, it is decided to continue the following studies with the imprint dimensions of the fin $\mathrm{Ir}-7 \mathrm{~mm}$ as its heat transfer value is the maximum among the investigated models and its total pressure drop increase compared to the corresponding plate fin is modest.

\subsection{The effect of protrusion length between two fins}

The geometrical dimensions of protrusions which give the maximum heat transfer for fins with balcony, winglet and imprint are determined as the fins $B h-3 m m, W w-3 m m$ and $I r-7 m m$, respectively in the previous parts. However, the length of protrusions between fins $\left(L_{\mathrm{b}}, L_{\mathrm{W}}\right.$ and $\left.L_{\mathrm{i}}\right)$ is taken as $2.425 \mathrm{~mm}$ for all of the fins investigated so far. In this section of the study, the length of each type protrusion is changed and the effects on heat transfer and total pressure drop values are examined.

\subsubsection{The effect of balcony length}

The value of the length of balcony is varied between $1 \mathrm{~mm}$ and $2.425 \mathrm{~mm}$. The length values used in this part of investigation and the corresponding model names are summarized in Table 9. Since the numerical results of the previous parts indicates that the fin with a balcony height of $3 \mathrm{~mm}$ has the best performance, the geometrical dimensions (other than the length between two fins) of the fin Bh-3mm are maintained in this part of the study.

The numerical analysis of the fins with 9 different balcony length values are obtained from the Fluent software and summarized in Table 9. The heat transfer and pressure drop values of the fin wavy-d $2 \mathrm{~mm}$ are taken as $100 \%$ in this section again since the corresponding plate fin is wavy- $\mathrm{d} 2 \mathrm{~mm}$.

It can be concluded from the numerical results of this part of the study that as the balcony length approaches the midpoint of the gap between two fins, an increase in heat transfer value is obtained (the balcony of the model Lb- $1.5 \mathrm{~mm}$ is exactly placed at the middle point of the gap between two fins). It is also observed that pressure drop values of the fins with balconies, whose length

Table 9

Balcony length values and heat transfer, total pressure drop values of the investigated fins.

\begin{tabular}{llllll}
\hline Model name & $\begin{array}{l}L_{\mathrm{b}} \\
(\mathrm{mm})\end{array}$ & $\begin{array}{l}Q \text { (per } \\
\text { segment) } \\
(\mathrm{W})\end{array}$ & $\begin{array}{l}\text { Normalized } \\
Q(\%)\end{array}$ & $\begin{array}{l}\text { Total pressure } \\
\text { drop (Pa) }\end{array}$ & $\begin{array}{l}\text { Normalized } \\
\text { total pressure } \\
\text { drop (\%) }\end{array}$ \\
\hline wavy-d2mm & 0 & 24.9176 & 100 & 3.0816 & 100 \\
Lb-2.425mm & 2.425 & 24.9717 & 100.217 & 3.2108 & 104.193 \\
Lb-2.2mm & 2.2 & 24.9765 & 100.236 & 3.2303 & 104.825 \\
Lb-2mm & 2 & 24.9928 & 100.302 & 3.2442 & 105.276 \\
Lb-1.8mm & 1.8 & 25.0075 & 100.361 & 3.2494 & 105.445 \\
Lb-1.6mm & 1.6 & 25.0100 & 100.371 & 3.2442 & 105.276 \\
Lb-1.5mm & 1.5 & 25.0114 & 100.376 & 3.2376 & 105.062 \\
Lb-1.4mm & 1.4 & 25.0074 & 100.360 & 3.2299 & 104.812 \\
Lb-1.2mm & 1.2 & 24.9952 & 100.311 & 3.2080 & 104.102 \\
Lb-1mm & 1 & 24.9730 & 100.222 & 3.1829 & 103.287 \\
\hline
\end{tabular}

is around the midpoint of the gap between two fins, are the highest. Since at the midpoint of the gap between two fins the flue gas velocity is higher, the block effect of the balconies placed around this point causes bigger pressure drop values. According to the results of this part of the study, it is decided to continue the following parts with the dimensions of the balcony of the fin Lb- $1.5 \mathrm{~mm}$, which gives the maximum heat transfer and reasonable total pressure drop value.

\subsubsection{The effect of winglet length}

Similar to the balcony length, the winglet length is changed between $1.3 \mathrm{~mm}$ and $2.425 \mathrm{~mm}$ and the effects are observed. The fin with a winglet width of $3 \mathrm{~mm}$ is chosen according to the numerical results of the previous parts of the study. So, the geometrical dimensions (other than the length between two fins) of the fin Ww-3mm are kept constant in this section. The winglet length values used in this section of the study are given in Table 10.

Similar to the previous cases, the results of the fin wavy- $d 2 \mathrm{~mm}$ are also presented (as 100\%) for comparison. The winglet length influence on the heat transfer and total pressure drop values are also shown in Table 10.

It is found in this part of the study that the fin with a winglet length value of $1.8 \mathrm{~mm}$ has the best heat transfer performance. Another conclusion is that as the winglet length is decreased it is observed a decrease in the pressure drop values. This result stems from the fact that as the winglet length is decreased, the flue gas flow area increases and less pressure drop values are encountered. The fin Lw-1.8mm is chosen considering the numerical results of this part of the study for the following parts of the investigation.

\subsubsection{The effect of imprint length}

Finally, the investigation for imprint length is performed. $L_{\mathrm{i}}$ values, taken between $1.3 \mathrm{~mm}$ and $2.425 \mathrm{~mm}$, are given in Table 11 . The fin $\mathrm{Ir}-7 \mathrm{~mm}$, with an imprint radius of $7 \mathrm{~mm}$, is taken as the base fin according to previous study results and its geometrical dimensions except the length of imprint $\left(L_{\mathrm{i}}\right)$ are maintained throughout this part of the study. Similar to the previous parts of the study, the results of fin wavy-d2mm, which is the plate fin with the same geometrical dimensions, are also presented and comparisons are made by taking its results as $100 \%$. The change in heat transfer and total pressure drop values of the investigated fins are presented in Table 11 as well.

The results of this part of the study indicate that the decrease in imprint length results in reduction in both heat transfer and pressure drop values. This is an expected result, because when the imprint length is increased the flue gas flow path is lengthened and greater obstacle against the flue gas flow is created. Consequently, higher heat transfer and total pressured drop characteristics are observed with increasing imprint length. According to the obtained numerical results, it is decided to use the dimensions of the model $\mathrm{Li}-2.425 \mathrm{~mm}$ in the following parts of the study.

\section{Table 10}

Winglet length values and heat transfer, total pressure drop values of the investigated fins.

\begin{tabular}{llllll}
\hline Model name & $\begin{array}{l}L_{\mathrm{w}} \\
(\mathrm{mm})\end{array}$ & $\begin{array}{l}Q \text { (per } \\
\text { segment) } \\
(\mathrm{W})\end{array}$ & $\begin{array}{l}\text { Normalized } \\
Q(\%)\end{array}$ & $\begin{array}{l}\text { Total pressure } \\
\text { drop (Pa) }\end{array}$ & $\begin{array}{l}\text { Normalized } \\
\text { total pressure } \\
\text { drop (\%) }\end{array}$ \\
\hline wavy-d2mm & 0 & 24.9176 & 100 & 3.0816 & 100 \\
Lw-2.425mm & 2.425 & 24.9686 & 100.205 & 3.3000 & 107.087 \\
Lw-2.2mm & 2.2 & 24.9747 & 100.229 & 3.2894 & 106.743 \\
Lw-2mm & 2 & 24.9860 & 100.275 & 3.2726 & 106.198 \\
Lw-1.8mm & 1.8 & 24.9964 & 100.316 & 3.2494 & 105.445 \\
Lw-1.6mm & 1.6 & 24.9948 & 100.310 & 3.2247 & 104.644 \\
Lw-1.4mm & 1.4 & 24.9860 & 100.275 & 3.1977 & 103.768 \\
Lw-1.3mm & 1.3 & 24.9781 & 100.243 & 3.1853 & 103.365 \\
\hline
\end{tabular}


Table 11

Imprint length values and heat transfer, total pressure drop values of the investigated fins.

\begin{tabular}{llllll}
\hline Model name & $\begin{array}{l}L_{\mathrm{i}} \\
(\mathrm{mm})\end{array}$ & $\begin{array}{l}Q \text { (per } \\
\text { segment) } \\
(\mathrm{W})\end{array}$ & $\begin{array}{l}\text { Normalized } \\
Q(\%)\end{array}$ & $\begin{array}{l}\text { Total pressure } \\
\text { drop (Pa) }\end{array}$ & $\begin{array}{l}\text { Normalized } \\
\text { total pressure } \\
\text { drop (\%) }\end{array}$ \\
\hline wavy-d2mm & 0 & 24.9176 & 100 & 3.0816 & 100 \\
$\mathrm{Li}-2.425 \mathrm{~mm}$ & 2.425 & 25.0476 & 100.522 & 3.2707 & 106.136 \\
$\mathrm{Li}-2.2 \mathrm{~mm}$ & 2.2 & 25.0296 & 100.449 & 3.2395 & 105.124 \\
$\mathrm{Li}-2 \mathrm{~mm}$ & 2 & 25.0163 & 100.396 & 3.2131 & 104.267 \\
$\mathrm{Li}-1.8 \mathrm{~mm}$ & 1.8 & 25.0023 & 100.340 & 3.1897 & 103.508 \\
$\mathrm{Li}-1.6 \mathrm{~mm}$ & 1.6 & 24.9872 & 100.279 & 3.1691 & 102.839 \\
$\mathrm{Li}-1.4 \mathrm{~mm}$ & 1.4 & 24.9738 & 100.226 & 3.1499 & 102.216 \\
$\mathrm{Li}-1.3 \mathrm{~mm}$ & 1.3 & 24.9654 & 100.192 & 3.1415 & 101.944 \\
\hline
\end{tabular}

\subsection{The effect of protrusion location on fin}

The geometrical dimensions of fin, fin tube and three different protrusions are determined using the numerical heat transfer and total pressure drop values obtained from Fluent software in the previous parts. However, the protrusions are always placed at location 5, shown in Fig. 2(f). The location of the protrusions on the plate fin has also an important influence on heat transfer and pressure drop characteristics. So, in this section the best location of the balcony, winglet and imprint type protrusions will be determined. The placements of the protrusions on different fin models are given in Table 12.

The dimensions of the models Lb- $1.5 \mathrm{~mm}$, Lw- $1.8 \mathrm{~mm}$ and $\mathrm{Li}-2.425 \mathrm{~mm}$ are used in this part since they are determined as the best in the previous sections of the study. Imprint type protrusion cannot be placed at locations 1 and 7 because of its greater radius value than the distances between the location 1 and lower point of the fin and location 7 and the upper point of the fin.

A total of 19 different fins are analyzed numerically in this part of the study and the numerical results are tabulated in Table 13. Here also the fin wavy- $\mathrm{d} 2 \mathrm{~mm}$ represents the corresponding plate fin and its heat transfer and total pressure drop values are assumed as $100 \%$ for the calculation of normalized values of the other fin models.

The best protrusion location for all protrusion types is determined as location 4 in terms of heat transfer performance since the maximum heat transfer value can be obtained when protrusion is placed at location 4 . This result stems from the fact that the flue gas is better directed to the fin tube when the protrusion is present at this location. Another conclusion is that fins with imprint type protrusion give better heat transfer performance than the fins with balcony or winglet type protrusions. It is also observed that the pressure drop values are the highest when protrusions are placed at location 3 , which coincides to the center of fin tube. At location 3, the flue gas flow area takes its minimum value, so the pressure drop value increase can be explained with this flow area reduction. The results of the present study show

Table 12

Fins with protrusions placed at different locations.

\begin{tabular}{llll}
\hline Model name & & & \\
\hline With & With & With & Location \\
balcony & winglet & imprint & \\
\hline B1 & W1 & - & 1 \\
B2 & W2 & I2 & 2 \\
B3 & W3 & I3 & 3 \\
B4 & W4 & I4 & 4 \\
B5 & W5 & I5 & 5 \\
B6 & W6 & I6 & 6 \\
B7 & W7 & - & 7 \\
\hline
\end{tabular}

Table 13

Heat transfer and total pressure drop values of fins with protrusions placed at different locations.

\begin{tabular}{|c|c|c|c|c|c|}
\hline & $\begin{array}{l}\text { Model } \\
\text { name }\end{array}$ & $\begin{array}{l}Q \text { (per } \\
\text { segment) } \\
(W)\end{array}$ & $\begin{array}{l}\text { Normalized } \\
Q(\%)\end{array}$ & $\begin{array}{l}\text { Total } \\
\text { pressure } \\
\text { drop }(\mathrm{Pa})\end{array}$ & $\begin{array}{l}\text { Normalized } \\
\text { total pressure } \\
\text { drop }(\%)\end{array}$ \\
\hline \multirow{6}{*}{$\begin{array}{l}\text { Fins with } \\
\text { balcony }\end{array}$} & wavy-d2mm & 24.9176 & 100 & 3.0816 & 100 \\
\hline & B1 & 24.9897 & 100.289 & 3.2742 & 106.250 \\
\hline & B2 & 25.0042 & 100.348 & 3.3224 & 107.814 \\
\hline & B3 & 25.0121 & 100.379 & 3.3450 & 108.548 \\
\hline & B4 & 25.0136 & 100.385 & 3.3060 & 107.282 \\
\hline & B5 & 25.0114 & 100.376 & 3.2376 & 105.062 \\
\hline \multirow{6}{*}{$\begin{array}{l}\text { Fins with } \\
\text { winglet }\end{array}$} & B6 & 25.0084 & 100.364 & 3.1973 & 103.755 \\
\hline & B7 & 25.0029 & 100.342 & 3.1655 & 102.723 \\
\hline & W1 & 24.9672 & 100.199 & 3.3086 & 107.366 \\
\hline & W2 & 24.9767 & 100.237 & 3.4191 & 110.952 \\
\hline & W3 & 24.9912 & 100.295 & 3.4521 & 112.023 \\
\hline & W4 & 25.0004 & 100.332 & 3.3588 & 108.995 \\
\hline \multirow{8}{*}{$\begin{array}{l}\text { Fins with } \\
\text { imprint }\end{array}$} & W5 & 24.9964 & 100.316 & 3.2494 & 105.445 \\
\hline & W6 & 24.9904 & 100.292 & 3.2063 & 104.047 \\
\hline & W7 & 24.9731 & 100.223 & 3.1751 & 103.034 \\
\hline & $\mathrm{I} 2$ & 25.0339 & 100.467 & 3.3565 & 108.921 \\
\hline & I3 & 25.0496 & 100.530 & 3.3799 & 109.680 \\
\hline & 14 & 25.0527 & 100.542 & 3.3438 & 108.509 \\
\hline & I5 & 25.0476 & 100.522 & 3.2707 & 106.136 \\
\hline & I6 & 25.0346 & 100.470 & 3.2269 & 104.715 \\
\hline
\end{tabular}

a good similarity with the results reported by Bilir et al. [26]. They found the best location for different protrusions as the fin tube upper point. However they did not take into account the half point of the fin tube center and fin tube upper point (location 4 in the current study). They found lower heat transfer values for the fin with winglet when the winglet is placed at the bottom part of the fin. However there are two factors which influenced the heat transfer negatively for their cases. The first one, they used circular fin tubes and the second one is that the winglet was placed at a distance determined by a radius of $13 \mathrm{~mm}$ form the center of fin tube when it is placed at the lower part of the fin. In this study, elliptic fin tubes are used and more suitable placement is selected for the winglets.

\subsection{Use of three different protrusions together}

The individual effects of plate fin geometry and protrusion dimensions and location on fin are analyzed step by step in the above sections of the study. The best fin found in the previous section is used to continue the next step of the study. Finally, the best fins with only one protrusion are determined as the fins B4, W4 and I4. However, the case for which the three protrusions are placed on the plate fin surface at the same time needs also to be investigated. In this way, the cumulative effect of three protrusions

Table 14

Protrusion placement on the fins with three different protrusions.

\begin{tabular}{llll}
\hline Model name & $\begin{array}{l}\text { Balcony } \\
\text { location }\end{array}$ & $\begin{array}{l}\text { Winglet } \\
\text { location }\end{array}$ & $\begin{array}{l}\text { Imprint } \\
\text { location }\end{array}$ \\
\hline I2B4W5 & 4 & 5 & 2 \\
I2W4B5 & 5 & 4 & 2 \\
I3B5W6 & 5 & 6 & 3 \\
I3W5B6 & 6 & 5 & 3 \\
I4B2W6 & 2 & 6 & 4 \\
I4W2B7 & 7 & 2 & 4 \\
I5B2W3 & 2 & 3 & 5 \\
I5W2B3 & 3 & 2 & 5 \\
I6B3W4 & 3 & 4 & 6 \\
I6W3B4 & 4 & 3 & 6 \\
\hline
\end{tabular}


Table 15

Heat transfer and total pressure drop values of fins with three different protrusions.

\begin{tabular}{lllll}
\hline Model name & $\begin{array}{l}Q \text { (per } \\
\text { segment) } \\
(\mathrm{W})\end{array}$ & $\begin{array}{l}\text { Normalized } \\
Q(\%)\end{array}$ & $\begin{array}{l}\text { Total pressure } \\
\text { drop (Pa) }\end{array}$ & $\begin{array}{l}\text { Normalized } \\
\text { total pressure } \\
\text { drop (\%) }\end{array}$ \\
\hline wavy-d2mm & 24.9176 & 100 & 3.0816 & 100 \\
I2B4W5 & 25.1973 & 101.122 & 3.7878 & 122.917 \\
I2W4B5 & 25.2284 & 101.247 & 3.8385 & 124.562 \\
I3B5W6 & 25.1806 & 101.055 & 3.6812 & 119.457 \\
I3W5B6 & 25.1982 & 101.126 & 3.6804 & 119.431 \\
I4B2W6 & 25.1570 & 100.961 & 3.7099 & 120.389 \\
I4W2B7 & 25.1922 & 101.102 & 3.7642 & 122.151 \\
I5B2W3 & 25.2396 & 101.292 & 3.9971 & 129.709 \\
I5W2B3 & 25.1987 & 101.128 & 3.9220 & 127.272 \\
I6B3W4 & 25.2212 & 101.218 & 3.8469 & 124.835 \\
I6W3B4 & 25.1900 & 101.093 & 3.8907 & 126.256 \\
\hline
\end{tabular}

will be revealed. So, it is decided to try some combinations of protrusion placement on the plate fin. Since the biggest increase for heat transfer is obtained from the imprint type protrusion, the cases when it is placed at location 2, 3, 4, 5 and 6 are investigated. The placement of the other protrusions is decided according to the results obtained in the previous sections. The fins with three different protrusions investigated in this part of the study are presented in Table 14

Ten different fins with three different types of protrusions are modeled and numerical solution of heat transfer and fluid flow problems are obtained using Fluent software. The results of numerical analysis are given in Table 15 . The comparison with the corresponding plate fin wavy- $\mathrm{d} 2 \mathrm{~mm}$ is also made in this section.

0.000 .180 .360 .540 .720 .901 .081 .261 .441 .621 .801 .982 .162 .342 .522 .702 .883 .063 .243 .423 .60

a

$(\mathrm{m} / \mathrm{s})$

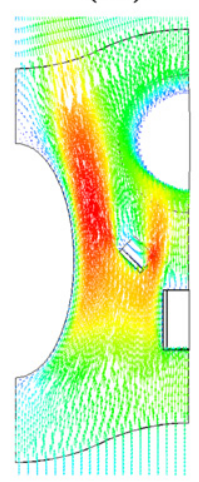

b

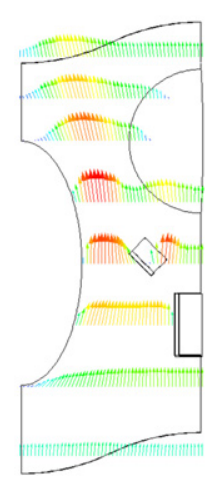

Fig. 8. Velocity vectors for the model I5B2W3 (a) at the middle plane of the gap between two fins (b) at various levels at the middle plane of the gap between two fins.

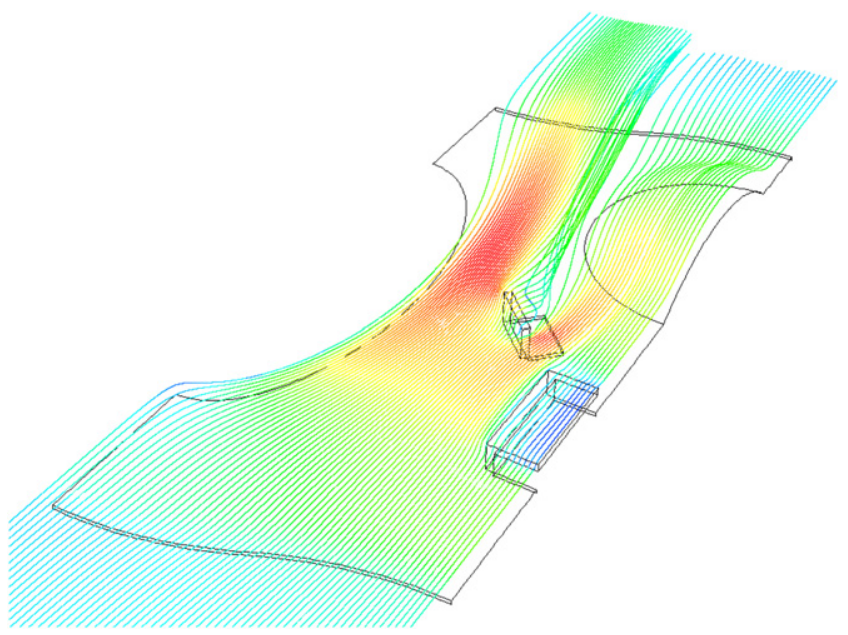

Fig. 9. Pathlines released from the inlet of the flue gas at the middle plane of the gap between two fins for the model I5B2W3.

The velocity vectors and the pathlines released from the inlet of flue gas at the middle plane of the gap between two fins for the model I5B2W3, which gives the best heat transfer performance, are presented in Figs. 8 and 9, respectively.

It is observed that the flue gas flow acceleration with the use of three protrusions together is higher compared to the case of only one protrusion usage. In addition, the flue gas flow path is longer. Consequently, higher heat transfer results are obtained when three protrusions are placed on the plate fin at the same time.

When the numerical results of the final section of the study are investigated, it is seen that the placement of balcony at location 2 , winglet at location 3 and imprint at location 5 is the best combination in terms of heat transfer performance. This configuration gives $1.292 \%$ more heat transfer value compared to the plate fin with the same geometrical dimensions (wavy- $\mathrm{d} 2 \mathrm{~mm}$ ). Besides this increase in heat transfer, the fin I5B2W3 also causes a $29.709 \%$ higher total pressure drop compared to the fin wavy-d2mm. If we compare the fin I5B2W3 with the plate fin whose heat transfer performance is the worst (the fin c- $12.5 \mathrm{~mm}$, with a cylindrical fin tube, $L=40 \mathrm{~mm}$ and $L_{1}=12.5 \mathrm{~mm}$ ), it is seen that the fin I5B2W3 provides a heat transfer increase of $3.607 \%$ and a total pressure increase of $1.012 \%$. The numerical optimization of a fin-tube type heat exchanger in the chosen geometrical ranges is completed with this final study and the best fin is determined as the fin I5B2W3.

\section{Conclusions}

In this study, the optimization of the fin, fin tube and protrusion geometries of a finned tube heat exchanger is performed. Additionally, the best location of the protrusions on the plate fin surface is determined. The investigated parameters of the plate fin and fin tube geometry are; fin height and fin tube thickness, fin tube location and ellipticity, fin shape (waviness). Furthermore, three different protrusions are examined in the study. These are balcony, winglet and imprint type protrusions. The individual as well as cumulative effects of these three different protrusions on the heat transfer and pressure drop characteristics of the finned tube heat exchanger are also investigated numerically. The parameters examined for protrusions can be summarized as; protrusion height, width and radius, protrusion length between two fins and protrusion location on fin. The numerical analyses are performed using boundary conditions which are taken from the actual operating conditions of a combi boiler heater taken as the practical model for the present study. 
The results of the parametric study about plate fin geometry indicate that a plate fin with a fin height value of $40 \mathrm{~mm}$, a fin tube thickness value of $0.6 \mathrm{~mm}$, a fin tube, placed at a $18.5 \mathrm{~mm}$ away from the bottom point of the fin, with an ellipticity value of 0.45 and a wave height of $2 \mathrm{~mm}$ provides the best performance. The parametric study about the protrusions reveals that the balcony with a $3 \mathrm{~mm}$ height and a $1.5 \mathrm{~mm}$ length in the gap between two fins, the winglet with a $3 \mathrm{~mm}$ width and a $1.8 \mathrm{~mm}$ length in the gap between two fins and the imprint with a $7 \mathrm{~mm}$ radius and a $2.425 \mathrm{~mm}$ length in the gap between two fins are the best ones among the investigated cases. The best location of each protrusion on the fin surface is found as location 4 shown in Fig. 2(f). Finally, the investigation of the cumulative effect of three protrusions shows that the use of three protrusions provides better heat transfer performance compared to the case with only one protrusion. However, a pressure drop increase is also observed with the use of three protrusions together. But it is also observed that the flue gas pressure drop increase due to the usage of protrusions can be considered as modest. The best fin is determined as I5B2W3 according to the obtained numerical results and the optimization study is concluded with this outcome.

\section{References}

[1] L.A.O. Rocha, F.E.M. Saboya, J.V.C. Vargas, A comparative study of elliptical and circular sections in one- and two row tubes and plate fin heat exchangers, Int. J. Heat Fluid Fl. 18 (1997) 247-252.

[2] B. Kundu, P.K. Das, Optimum dimensions of plate fins for fin-tube heat exchangers, Int. J. Heat Fluid Fl. 18 (1997) 530-537.

[3] R.R. Mendez, M. Sen, K.T. Yang, R. McClain, Effect of fin spacing on convection in a plate fin and tube heat exchanger, Int. J. Heat Mass Transfer 43 (2000) 39-51.

[4] S. Saboya, F.E.M. Saboya, Experiments on elliptic sections in one- and two-row arrangements of plate fin and tube heat exchangers, Exp. Therm. Fluid Sci. 24 (2001) 67-75.

[5] J.Y. Kim, T.H. Song, Microscopic phenomena and macroscopic evaluation of heat transfer from plate fins/circular tube assembly using naphthalene sublimation technique, Int. J. Heat Mass Transfer 45 (2002) 3397-3404.

[6] A. Erek, B. Özerdem, L. Bilir, Z. İlken, Effect of geometrical parameters on heat transfer and pressure drop characteristics of plate fin and tube heat exchangers, Appl. Therm. Eng. 25 (2005) 2421-2431.

[7] C.C. Wang, W.L. Fu, C.T. Chang, Heat transfer and friction characteristics of typical wavy fin-and-tube heat exchangers, Exp. Therm. Fluid Sci. 14 (1997) 174-186.

[8] M. Abu Madi, R.A. Johns, M.R. Heikal, Performance characteristics correlation for round tube and plate finned heat exchangers, Int. J. Refrigeration 21 (7) (1998) 507-517.

[9] W.M. Yan, P.J. Sheen, Heat transfer and friction characteristics of fin-and- tube heat exchangers, Int. J. Heat Mass Transfer 43 (2000) 1651-1659.
[10] G. Lozza, U. Merlo, An experimental investigation of heat transfer and friction losses of interrupted and wavy fins for fin-and-tube heat exchangers, Int. J. Refrigeration 24 (2001) 409-416.

[11] W. Pirompugd, S. Wongwises, C.C. Wang, Simultaneous heat and mass transfer characteristics for wavy fin-and-tube heat exchangers under dehumidifying conditions, Int. J. Heat Mass Transfer 49 (2006) 132-143.

[12] M.C. Gentry, A.M. Jacobi, Heat transfer enhancement by delta-wing vortex generators on a flat plate: vortex interactions with the boundary layer, Exp. Therm. Fluid Sci. 14 (1997) 231-242.

[13] Y. Chen, M. Fiebig, N.K. Mitra, Heat transfer enhancement of a finned oval tube with punched longitudinal vortex generators in-line, Int. J. Heat Mass Transfer 41 (1998) 4151-4166.

[14] P.M. Ligrani, G.I. Mahmood, J.L. Harrison, C.M. Clayton, D.L. Nelson, Flow structure and local Nusselt number variations in a channel with dimples and protrusions on opposite walls, Int. J. Heat Mass Transfer 44 (2001) 4413-4425.

[15] C.C. Wang, J. Lo, Y.T. Lin, M.S. Liu, Flow visualization of wave-type vortex generator having inline fin-tube arrangement, Int. J. Heat Mass Transfer 45 (2002) 1933-1944.

[16] G.I. Mahmood, P.M. Ligrani, Heat transfer in a dimpled channel: combined influences of aspect ratio, Reynolds number, and flow structure, Int. J. Heat Mass Transfer 45 (2002) 2011-2020.

[17] J.S. Leu, Y.H. Wu, J.Y. Jang, Heat transfer and fluid flow analysis in plate-fin and tube heat exchangers with a pair of block shape vortex generators, Int. J. Heat Mass Transfer 47 (2004) 4327-4338.

[18] A.D. Sommers, A.M. Jacobi, Air-side heat transfer enhancement of a refrigerator evaporator using vortex generation, Int. J. Refrigeration 28 (2005) 1006-1017.

[19] S.M. Pesteei, P.M.V. Subbararo, R.S. Agarwal, Experimental study of the effect of winglet location on heat transfer enhancement and pressure drop in fintube heat exchangers, Appl. Therm. Eng. 25 (2005) 1684-1696.

[20] C.B. Allison, B.B. Dally, Effect of a delta-winglet vortex pair on the performance of a tube-fin heat exchanger, Int. J. Heat Mass Transfer 50 (2007) 5065-5072.

[21] H. Lienhart, M. Breuer, C. Köksoy, Drag reduction by dimples? - a complementary experimental/numerical investigation, Int. J. Heat Fluid Fl. 29 (2008) 783-791.

[22] J.M. Wu, W.Q. Tao, Numerical study on laminar convective heat transfer in a channel with longitudinal vortex generator. Part A: Verification of field synergy principle, Int. J. Heat Mass Transfer 51 (2008) 1179-1191.

[23] J.M. Wu, W.Q. Tao, Numerical study on laminar convective heat transfer in a channel with longitudinal vortex generator. Part B: Parametric study of major influence factors, Int. J. Heat Mass Transfer 51 (2008) 3683-3692.

[24] L.T. Tian, Y.L. He, Y.G. Lei, W.Q. Tao, Numerical study of fluid flow and heat transfer in a flat-plate channel with longitudinal vortex generators by applying field synergy principle analysis, Int. Commun. Heat Mass 36 (2009) 111-120.

[25] P. Chu, Y.L. He, Y.G. Lei, L.T. Tian, R. Li, Three-dimensional numerical study on fin-and-oval- tube heat exchanger with longitudinal vortex generators, Appl. Therm. Eng. 29 (2009) 859-876.

[26] L. Bilir, B. Ozerdem, A. Erek, Z. Ilken, Heat transfer and pressure drop characteristics of fin-tube heat exchangers with different types of vortex generator configurations, J. Enhanc. Heat Transfer 17 (3) (2010) 243-256.

[27] S. Kakaç, Y. Yener, Convective Heat Transfer, second ed. CRC Press, Begell House, Boca Raton, Florida, 1995.

[28] F.R. Incropera, P.D. DeWitt, T.L. Bergman, A. Lavine, Fundamentals of Heat and Mass Transfer, sixth ed. Wiley, River Street, Hoboken, NJ, 2007. 